\title{
Current Advances and Future Perspectives in Extrusion-based Bioprinting
}

\author{
Ibrahim T. Ozbolat and Monika Hospodiuk \\ Engineering Science and Mechanics Department, The Pennsylvania State University, University Park, PA, 16802 \\ The Huck Institutes of the Life Sciences, The Pennsylvania State University, University Park, PA, 16802
}

\begin{abstract}
Extrusion-based bioprinting (EBB) is a rapidly growing technology that has made substantial progress during the last decade. It has great versatility in printing various biologics, including cells, tissues, tissue constructs, organ modules and microfluidic devices, in applications from basic research and pharmaceutics to clinics. Despite the great benefits and flexibility in printing a wide range of bioinks, including tissue spheroids, tissue strands, cell pellets, decellularized matrix components, micro-carriers and cell-laden hydrogels, the technology currently faces several limitations and challenges. These include impediments to organ fabrication, the limited resolution of printed features, the need for advanced bioprinting solutions to transition the technology bench to bedside, the necessity of new bioink development for rapid, safe and sustainable delivery of cells in a biomimetically organized microenvironment, and regulatory concerns to transform the technology into a product. This paper, presenting a first-time comprehensive review of EBB, discusses the current advancements in EBB technology and highlights future directions to transform the technology to generate viable end products for tissue engineering and regenerative medicine.
\end{abstract}

Keywords: Extrusion-based bioprinting, biofabrication, tissue and organ printing, bioink 


\section{Introduction}

The pressure or extrusion-based method has been used for quite a long time for various processes such as shape forming of metals and plastics [1]. In the late 1990s, with the emergence of fused-deposition modeling (FDM), the extrusion-based solid-freeform fabrication approach demonstrated three-dimensional (3D) printing of intricate geometries with controlled porous architecture [2]. This innovative approach was later introduced into tissue engineering via 3D printing of porous scaffolds [3], which act as temporary housing for cells to support their attachment, growth and proliferation. In this regard, several pioneering works have been demonstrated in the literature, including the development of printable biomaterials and 3D printing approaches for scaffold fabrication by Hutmatcher's group [4-6] and efforts in investigating modeling and design aspects for solid-freeform fabrication of tissue scaffolds by Hollister's group [7-9]. With the advent of printing living cells, the emergence of the first bioprinting technologies via other means such as laser-based bioprinting [10] and inkjet-based bioprinting [11], the investigation of extrusion-based bioprinting (EBB) [12] has begun. While there is a misconception about the term "bioprinting" as it has been interchangeably used with 3D printing of inert materials applied to tissue engineering, the authors consider providing a definition of bioprinting to the reader. Bioprinting can be defined as the spatial patterning of living cells and other biologics by stacking and assembling them using a computer-aided layerby-layer deposition approach for fabrication of living tissue and organ analogs for tissue engineering, regenerative medicine, pharmacokinetic, and other biological studies [13], and shall not be used interchangeably with 3D printing of inert materials. 
The first investigation in the context of EBB was the printing of living cells using the bioplotting approach, in which hydrogel bioink was extruded and bioplotted into a liquid medium, resulting in high flexural and mechanical strength and cell proliferation rate [14]. The fledgling technology later received enormous attention and advanced rapidly. Although several groups, including Sun and his coworkers $[15,16]$, investigated the technology by encapsulating cells in hydrogel solutions, the versatility of the technology allowed other researchers to adopt novel bioink materials into the EBB technology. In 2004, Mironov and Forgacs introduced the concept of printing scaffold-free cell aggregates for bioprinting living tissues and organs [1719]. They considered printing cells in clusters in a spheroid shape on a hydrogel glue called "biopaper" [20] and investigated bioprinting vascular constructs in 3D. After some initial attempts at bioprinting spheroids and assembling them vertically, the technology rapidly evolved into generating feasible outcomes and resulted in the fabrication of blood vessels [21]. Further modifications have been applied to the technology, and it currently enables printing tissue constructs that do not require significant vascularization such as thin or hollow (i.e., skin, nerve and vasculature) and avascular (i.e., cartilage) tissues [22].

Due its versatility, affordability and ability to print porous constructs, EBB is now utilized by numerous researchers worldwide, and the technology has already paved the way to bioprint cells [23-25], tissues [26], tissue constructs [27], organ modules [28] and tissue/organ-on-achip devices [27], with long-term expectations of printing functional scale-up organs [29]. A wide variety of tissue constructs have been successfully engineered by means of EBB, including but not limited to cartilage [30], vasculature [21], bone [31], skin [32], liver [25,33] and cardiac [34] tissue constructs. Currently, EBB technology has been commercialized by several 
companies, and a number of bioprinters are widely available for new bioprinting researchers entering the field or researchers using bioprinting as an application in fields such as biology, pharmacy and medicine [35]. The technology has been adopted into various fields and includes basic research in areas such as cancer research [36], tissue engineering [37,38], pharmaceutics for drug testing [39] and tissue printing for transplantation and clinics [40].

Although several reviews have been published in the area of bioprinting of tissues and organs $[22,41,42]$, no study has investigated EBB solely and thoroughly. This article presents a comprehensive review of EBB for the first time covering its working principles, applicable bioink materials, process configurations and bioprinter technologies and providing the reader with current advances and future perspectives and directions. Transformative approaches should also be discussed, including transitional approaches to get the technology from bench to bedside, advancements in the area of bioink processing for EBB, bioprinting-mediated genes for advanced gene therapy applications, bioprinting of new types of organs and other novel concepts that have the potential to make a breakthrough in EBB science and technology.

\section{Background}

\subsection{Working Principles}

The EBB technique is a combination of a fluid-dispensing system and an automated robotic system for extrusion and bioprinting, respectively [12]. During bioprinting, bioink is dispensed by a deposition system, under the control of a computer, resulting in the precise deposition of cells encapsulated in cylindrical filaments of desired 3D custom-shaped structures. This rapid fabrication technique provides better structural integrity due to the continuous deposition of filaments. Moreover, this method easily can incorporate computer 
software such as computer-aided design (CAD) software, which enables users to load a CAD file to automatically print the structure [43]. The CAD file can be obtained from medical images such as MRI and CT scans or a free-form design per demand [44].

The fluid-dispensing system can be driven by a pneumatic-, mechanical- (piston or screw-driven) or solenoid-based system, as shown in Fig. 1A pneumatic-based system utilizes pressurized air using a valve-free (Fig. 1A1) or a valve-based (Fig. 1A2) configuration. Although the valve-free configuration has been widely used due to its simplicity, the valve-based configuration can be preferable because of its controlled pressure and pulse frequency for highprecision applications [16]. Mechanical micro-extrusion systems utilize piston- (Fig. 1B1) or screw-driven (Fig. 1B2) configurations. The piston-driven configuration generally provides more direct control over the flow of bioink through the nozzle [45], while the screw-driven configuration may give more spatial control and is beneficial for dispensing bioinks with higher viscosities [46]. However, the screw-driven configuration can generate larger pressure drops along the nozzle, which can potentially harm the loaded cells. Thus, the rotating screw gear needs to be carefully designed in order to use it in EBB. Both types of mechanical microextrusion can work synergistically, i.e., the screw-driven configuration melts polycaprolactone (PCL) before deposition while the piston-driven syringes extrude hydrogel [47]. Solenoid microextrusion (Fig. 1C) utilizes electrical pulses to open a valve by canceling the magnetic pull force generated between a floating ferro-magnetic plunger and a ferro-magnetic ring magnet. A similar configuration can be developed using a piezoelectric-actuated system; however, it is not convenient for EBB while the process mode is droplet [16]. 


\subsection{Recent Achievements using EBB}

Several researchers have demonstrated EBB of tissue substitutes in the literature. Different cell types have been loaded and deposited in a wide range of biocompatible hydrogels. Recently, Billiet et al. used hepatocytes with gelatin methacrylamide hydrogel to engineer artificial liver tissue constructs [48]. Cell viability after deposition ranged up to $97 \%$. Horváth et al. demonstrated bioprinting of lung tissue analogues for the first time [23]. The architecture of the air-blood barrier was very precise, comparable to native tissue. Another group created lipid bilayers separating cell-encapsulated droplets [49]. The functionalization of membrane proteins caused the spontaneous creation and transmission of an electrical current along defined pathways. With this advancement, self-folding droplets can be used for isolating cancer cells from healthy tissue or releasing cells for diagnostic applications in the future. Melchels et al. performed a characterization of a new gelatin-methacrylamide bioink containing gellan gum and mannose [50]. They obtained various 3D structures (pyramid, hemisphere, hollow cylinder) with high cell viability, where hydrogel properties can be tailored by salt concentration. Another group bioprinted human adipose tissue-derived mesenchymal stem cells (hASCs) loaded in decellularized matrix components of adipose tissue [51]. The bioink was printed in precisely-defined and flexible dome-shape structures, and hASCs in bioprinted structures showed significantly higher adipogenic differentiation than hASCs cultured in nonprinted decellularized adipose tissue matrix components.

\subsection{Comparison of EBB with other Bioprinting Techniques}

The EBB technique has several advantages and disadvantages with respect to other bioprinting techniques, including droplet-based bioprinting (inkjet-based [52], 
electrohydrodynamic jetting [53,54] and acoustic-droplet ejection [55]) or laser-based bioprinting (stereolithography and its modifications [56], laser-guidance direct writing [10] and laser-induced forward transfer [57]). It has greater deposition and printing speed, which can facilitate scalability in a relatively short period of time. In addition, the hardware is affordable and a wide array of bioprinting technologies is commercially available. In addition, EBB enables bioprinting a wide array of bioinks, including cell aggregates $[18,20,37,58]$, cell-laden hydrogels [59-62], micro-carriers [63] and decellularized matrix components [64], while other techniques can only facilitate printing cell-laden hydrogels. Bioprinting high cell density is currently feasible only with EBB technologies, and the process is very biocompatible with reasonably small process-induced cell damage and injury compared to other techniques. Moreover, the technology is easy to implement and can be used by operators who have limited exposure to the technology. The last and most important point is that EBB enables bioprinting anatomically correct porous constructs [65], which is very challenging using other means (except for modifications of stereolithography [56]).

Despite its versatility and great benefits, EBB has some disadvantages when compared to other technologies. First of all, the resolution of the technology is very limited; the minimum feature size is generally over $100 \mu \mathrm{m}$ [66], which is considerably lower than the resolution in other bioprinting techniques [41]. Therefore, cells cannot be precisely patterned and organized due to limited resolution. In addition, the bioink, in liquid or sol-gel state, should possess shear thinning ability to overcome surface tension-driven droplet formation in order to be extruded in the form of cylindrical filaments. Gelation and solidification requirements during the extrusion process limits the hydrogels used in EBB. Furthermore, shear stress on the nozzle tip 
wall induces a significant drop in the number of living cells when the cell density is high [67]. The time it takes to bioprint large constructs also affects cell viability. Bioprinting into cell culture media is not practiced, so cells are exposed to dehydration and a lack of nutrients.

\section{The Bioink Consideration}

Extrusion-based bioprinting is very versatile in depositing a wide array of bioink types, including hydrogels [60-62], micro-carriers [63], tissue spheroids [18,20,37,58], cell pellet [68], tissue strands [69] and decellularized matrix components [64], as shown in Figure 2. This versatility originates due to the larger nozzle diameter ranges applied, the ability to deposit small building blocks in a fugitive liquid delivery medium, flexibility in nozzle tip design and the ability to extrude bioink in near solid-state. A general process configuration is illustrated in Fig. $3 \mathrm{~A}$, where cells in the abovementioned bioink components can be loaded and extruded through a microneedle.

\subsection{Hydrogels}

A wide variety of hydrogels have been experimented with in EBB. Depending on their crosslinking mechanism, hydrogels that are applicable in EBB can be classified into three groups: physical (temperature [70], and light [48]), enzymatic [71], and chemical (pH [72], ionic compound [73]) crosslinking. Several review papers have been published about hydrogels used in tissue engineering $[61,74]$; thus, this paper focuses only on bioprintable hydrogels and their applicability and performance in EBB. The reader is referred to the paper by Ahmed et al. [75] for detailed information about a wide variety of hydrogels. 
Alginic acid, or alginate, is a polysaccharide derived primarily from brown seaweed and bacteria. It is a family of natural copolymers of $\beta$-D-mannuronic acid (M) and $\alpha$-L-guluronic acid (G). Because of its biocompatibility, low price and fast gelation rate, alginate has been widely used in EBB [76-78]. Different EBB systems have been experimented with due to the instant gelation properties of the gel in ionic solutions of calcium $\left(\mathrm{Ca}^{2+}\right)$, such as calcium chloride, calcium carbonate or calcium sulfate. These mechanism are (i) bioplotting [14], (ii) bioprinting hydrogel with a secondary nozzle using crosslinker deposition or a spraying system [79], (iii) bioprinting using a coaxial nozzle-assisted system [80], (iv) bioprinting pre-crosslinked alginate and further crosslinking it thereafter [59] and (v) bioprinting alginate with an aerosol crosslinking process [81]. Although some researchers use the term "bioplotting" and "bioprinting" interchangeably, there is a misconception about the "bioplotting" term. In bioplotting approach (see Fig. 3B1), cells in a hydrogel solution are extruded into a plotting medium (crosslinker pool), where extrusion takes place within the pool and the bioprinted scaffold stays inside the pool until the process is completed. Therefore, extrusion of hydrogels without a crosslinker plotting medium shall not be classified under "bioplotting" approach. In bioplotting, the density of the extruded bioink needs to be greater than that of the plotting medium for successful deposition. By altering the temperature and the viscosity of the plotting medium, extrusion and deposition process can be controlled easily. In the second technique, shown in Fig. 3B2, the crosslinker solution is deposited or sprayed (in large liquid droplets) onto the bioprinted alginate using a secondary nozzle, where the secondary nozzle can rotate around the primary nozzle using a motorized system [82]. In the third technique (see Fig. 3B3), alginate is bioprinted using a coaxial nozzle apparatus; alginate is bioprinted through the core, and the 
crosslinker solution is ejected through the sheath section of the outer nozzle, which is slightly longer than the core nozzle, providing better control of the extrudability of the bioink. Using a similar approach but an opposite configuration in coaxial nozzle development, alginate was extruded for various applications such as creating multi-material fibers for controlled drug delivery $[83,84]$, bioprinting blood vessels $[85]$ or microfluidic channels for tissue engineering applications [86] and encapsulating cell pellet to grow cell aggregates in a strand shape [87]. In the fourth technique (see Fig. 3B4), pre-crosslinked alginate (with low crosslinker concentration) is bioprinted, providing a sufficient deposition quality of bioink and structural integrity of the scaffold, followed by enhancing crosslinking by exposing the bioprinted scaffold to a high concentration of crosslinker solution. In this approach, the mechanical properties of printed constructs are better, but the pressure level for the extrusion process is higher relative to the density of the precrosslinked hydrogel. In addition, the bioink is not even, which brings discontinuities and nonuniformities during extrusion. In the fifth approach, shown in Fig. 3B5, alginate is bioprinted onto a stage, where the crosslinker solution is fumed over the entire bioprinting space using an ultrasonic humidifier. The difference between the fifth and the spraying approach is that fuming process generates highly small particles of the crosslinker solution in near vapor state that can be uniformly distributed over the entire structure as oppose to the spraying approach. This enables simultaneous crosslinking between layers, generating mechanically and structurally integrated constructs. All these approaches have pros and cons, but it has been demonstrated that bioprinting pre-crosslinked alginate or using a coaxial nozzle-assisted cross-linker deposition system shows promising results in terms of printing accuracy and the ability to 3D bioprint tissue structures with well-integrated interlayers 
[80]. Despite these advantages, cells are unable to interact with the biomaterial matrix via cell surface receptors due to the strongly hydrophilic nature of alginate. Cells in alginate are quite immobilized and have limited proliferation and interaction capabilities. In addition, mechanical properties are limited when low concentration is used, which favors higher cell viability and proliferation capabilities. Besides, cells cannot adhere easily unless surface modifications are applied. Thus, researchers attempted to modify alginate using cell adhesion ligands containing the arginine-glycine-aspartic acid (RGD) amino acid sequence [88], collagen type I [89] or oxygenation [77], enabling significant improvement in cell adhesion, spreading and proliferation.

Chitosan is produced by deacetylation of chitin and it is well known for its non-toxic, biodegradable, antibacterial and antifungal properties and is used, for example as wound dressing [90]. Chitosan hydrogels are widely used in bone, skin, and cartilage tissue engineering, due to the analogous content of hyaluronic acid and glycosaminoglycans as in native tissue [91-94]. The shortcomings of chitosan are its slow gelation rate (up to 10 minutes after injection) and low mechanical properties; only highly viscous samples are able to hold the shape by themselves for several hours $[94,95]$. These limitations can be eliminated by blending chitosan with other hydrogels to strengthen it and gain control over its polymerization rate. Chitosan is dissolved in acid solutions and then crosslinked by ionic and covalent agents. Recently, a water-soluble form at neutral $\mathrm{pH}$ ranges was obtained with a gelation capability at about $40^{\circ} \mathrm{C}$ [96]. Using EBB, chitosan has been used in the fabrication of various scaffolds, such as microfluidic, perfusable channels [86], scaffolds with embedded adipose stem cells that successfully underwent chondrogenesis [97], and 3D printed scaffolds in order to study the 
inflammatory response of an organism [24]. Some of the bioprinting mechanisms presented in Figs. 3B1-5 can also be applied in the bioprinting of chitosan hydrogel.

Gelatin is a fibrous protein, obtained by partial hydrolysis of the triple helix structure of collagen into single-strain molecules [98]. Gelatin has good biocompatibility, high wateradsorbing ability and non-immunogenicity, and it is completely biodegradable in vivo [99]. Gelatin is a thermally reversible hydrogel, which is solid at low temperatures, with low mechanical properties and instability under physiological conditions. For EBB applications, various chemical and physical cues, such as metal ions or glutaraldehyde, have been used to improve its bioprintability and stability in physiological conditions $[100,101]$. In order to obtain a photopolymerizable hydrogel that is stable at $37^{\circ} \mathrm{C}$, gelatin was chemically modified with methacrylamide side groups. Crosslinking of the methacrylamide-modified gelatin was performed in the presence of a water-soluble photoinitiator [102]. The resulting gelatin methacrylate composite hydrogel (GelMA) was easily extruded through a pneumatic dispenser equipped with a UV-light source $[25,48]$ as shown in Fig. 3 C. The printability of GelMA is dependent on gel concentration, UV time exposure and cell density, and the duration and intensity of UV curing can affect cell viability, hydrogel density and stiffness $[25,48]$. Furthermore, temperature-sensitive gelatin has been used as a sacrificial material to fabricate 3D printed scaffolds with open fluidic channels [103]. Upon printing, gelatin can be liquefied after incubating the scaffold at $37^{\circ} \mathrm{C}$, leaving empty and perfusable channels. Such structures containing fluidic networks enable the flow of culture medium, oxygen and drugs throughout the constructed scaffold, promoting cell survival and functions in the long term. 
Hyaluronic acid (HA), also known as hyaluronan, is a natural nonsulfated glycosaminoglycan ubiquitous in almost all connective tissues [104]. Hyaluronic acid has been extensively used in clinics as a dermal filler and have lubricating properties as synovial fluid in loss function and pain-causing changes in articular joints [105]. During early embryogenesis, HA can be found in high concentration, and it has a crucial role in the regulation of cell behavior and functions such as movement, proliferation and angiogenesis. The tunable physical and biological properties of HA-based hydrogels make them an attractive material for 3D bioprinting applications. Hyaluronic acid is the major tissue ECM component of cartilage. Threedimensional printed chondrocyte-encapsulated HA hydrogel showed high viability compared to cells in collagen hydrogels [106]. However, HA has poor mechanical properties and is characterized by rapid degradation [107]. Enhancement of these properties to control the degradation rate is possible by chemical modification. By itself, HA does not have suitable features for EBB because of the abovementioned limitations. Nonetheless, it can be functionalized with UV-curable methacrylate (MA), since crosslinking is easily controlled with the time of photopolymerization [108]. The HA-MA keeps its crucial biological properties because of the enhanced mechanical properties given by methacrylate and by using a UVintegrated system as presented in Fig. 3 C. It is a suitable hydrogel for EBB with high printability capacity $[45,61,109,110]$. Another noteworthy co-hydrogel is poly(ethylene glycol), in which flexible chains provide elasticity and HA chains provide mechanical strength [107].

Poly(ethylene glycol) (PEG) or poly(ethylene oxide) (PEO) is widely used as an excipient in medicines and in non-pharmaceutical products [111-113]. The PEG-based hydrogels are biocompatible with reduced immunogenicity, are FDA approved (used in enzymes, i.e., mPEG 
per adenosine deaminase, mPEG-L-asparaginase and pegloticase; cytokines, i.e., pegloticase andpeginterferon alfa-2b; and growth factors i.e., pegfilgrastim, pegvisomant and methoxy polyethylene glycol-epoetin beta [114]) for internal use and can be crosslinked using physical, ionic or covalent crosslinks [115]. Photopolymerization of PEG-based hydrogels with tunable mechanical properties has attracted considerable attention in EBB systems. Using a UVintegrated system (as shown in Fig. 3C), Hockaday et al. used a photocrosslinkable polyethylene-glycol diacrylate (PEG-DA) for rapidly 3D printing of complex, mechanically heterogeneous and clinically sized aortic valve scaffolds. Scaffolds were seeded with porcine aortic valve interstitial cells and cultured for up to 21 days [116]. However, cells adhered on the surface of the scaffolds did not show any sign of spreading or proliferation, which makes PEG a good candidate for cell encapsulation vehicles, although it requires functionalization for culturing on the surface of scaffolds. The immobilization of cell adhesion sites and growth factors during the bioprinting process promotes cell proliferation and migration and tissue regeneration $[117,118]$.

Agarose is a galactose-based polymer material extracted from seaweed. Agarose hydrogel has thermosensitive and thermoreversible properties. A few different types of agarose are available in the market, depending on the hydroxyethylation that directly affects the melting temperature of agarose [119]. The most suitable agarose for EBB is low-melting- and low-gelling-temperature agarose, which is easy to liquefy and gels at $26-30^{\circ} \mathrm{C}$ [120], where gelation also depends on agarose concentration. In [121], it was shown that agarose was cytocompatibile, supports differentiation of hASCs, had suitable abilities for 3D cell encapsulation and had stable mechanical properties that mimic native cell niche. However, 
DNA, protein and proteoglycan biosynthesis of hASCs in Matrigel was significantly lower than that in alginate or gelatin hydrogels. An EBB configuration presented in Figure 3D1 can be used to bioprint low-melting-temperature agarose, where extruded agarose in liquid state rapidly solidifies when bioprinted onto a freezing stage. Campos et al. showed 3D bioprinted mesenchymal stem cells encapsulated in agarose hydrogel, where the entire construct was supported by fluorocarbon [122]. Cells were deposited to create tubular structures with almost $100 \%$ cell viability after 21 days. Because of the abovementioned properties, agarose is also very suitable for developing 3D cell-culture platforms, acting as a non-adhesive hydrogel for formation of cell aggregates and supporting cell aggregation due to its cell adhesion-inert nature $[21,123,124]$.

Collagen type I has been used extensively in tissue engineering as a growth substrate for 3D cell culture or as a scaffold material for cellular therapies [125]. Collagen type I molecules contain the amino acid sequence RGD binding to integrin receptors [126], which mediate the interactions between the cytoskeleton and ECM and serve as signal transducers, activating various intracellular signaling pathways and cell functions. Acid-soluble collagen molecules are crosslinked when the $\mathrm{pH}$, temperature and ionic strength are adjusted to near physiological values. Once neutralized at a $\mathrm{pH}$ ranging from 7 to 7.4 , collagen polymerizes within 30 to $60 \mathrm{~min}$ at $37^{\circ} \mathrm{C}$ [106], which makes it a good candidate for in situ bioprinting applications. The mechanism of collagen crosslinking is also suitable for in vitro EBB studies. It is ideal for the bioprinting process taking place when collagen starts polymerization. Extruded collagen is then incubated until full crosslinking is achieved. The printability feature was demonstrated as far back as 2004 by Smith et al. [72], where collagen type I containing bovine 
aortic endothelial cells (BAECs) was bioprinted using a pneumatic-driven EBB system. Although a configuration presented in Fig. 3D2 is used to bioprint collagen, where the bioink is kept in ice-cold temperature ranges and heated up to physically relevant temperature ranges, full crosslinking of collagen can be achieved in 30 minutes in incubation after bioprinting. Collagen type I was successfully 3D printed in combination with different cell types and in combination with natural or synthetic materials to enhance the bioprinting capability and the mechanical properties of native collagen [127]. Although collagen type I has some disadvantages, such as sensitivity to metalloproteinases and poor mechanical properties [128], it has been successfully used as a major biomaterial supporting other hydrogels such as fibrin [129].

Pluronic $^{\circledast}$ is a tri-block copolymer based on poly(ethylene glycol)-block, poly(propylene glycol)-block, and poly(ethylene glycol) (PEO-PPO-PEO) sequences. Pluronic has been approved by the Food and Drug Administration (FDA) and is used as a drug delivery carrier and as an injectable gel, in the treatment of burns and in other wound-healing applications [130,131]. The temperature sensitivity of Pluronic is based on the intermolecular association of PPO blocks leading to the formation of micelle structures above critical micelle temperature. For example, a $20 \%$ Pluronic $\mathrm{F}-127$ solution is sol at room temperature and gels above $20^{\circ} \mathrm{C}$; the sol-gel transition can be modified by changing the solution concentration [110]. F-127 has great potential in the EBB process $[130,132]$ but requires a special bioprinting apparatus. Thus, a thermally controlled nozzle system is required to solidify the bioink as extrusion takes place as presented in Fig. 3D2. When the bioink is loaded into the barrel in a liquid state, it is kept at low temperature using a cooling chamber if the melting temperature is below room temperature. A heating unit around the dispensing tip enables precise control of the temperature while the 
bioink is extruded. In this way, the bioink can be extruded in solid filament form. Optionally, a heating plate can be used to prevent melting of the hydrogel and loss of the structure and shape. Using Pluronic, spatially well-defined constructs can be printed accurately [72]. Despite its great benefits, F-127 has very weak mechanical and structural properties and possesses quick degradation as well as rapidly dissolving in aqueous solutions. Therefore, it can be considered chemically modified by blending with other polymers to improve the physical and mechanical properties of the resulting copolymer. Researchers have considered Pluronic F-127 as a sacrificial material (either considered a fugitive ink [132]) or a support material [133] to create a vascular network as discussed in details in Section 5.

Matrigel is a gelatinous protein mixture produced by mouse Engelbreth-Holm-Swarm sarcoma cells. One of its biggest advantages is promoting the differentiation of multiple cell types and outgrowth from tissue fragments [134]. Matrigel has been extensively studied as a candidate for cardiac tissue engineering [135]. Research results of Fedorovich et al. revealed that Matrigel promoted vascularization faster than Pluronic, alginate and agarose hydrogels [136]. Matrigel is a thermosensitive material but is not reversible. Once it crosslinks at $24-37^{\circ} \mathrm{C}$, it does not decrosslink when cooled. Gelation takes about 30 minutes and starts above $4^{\circ} \mathrm{C}$ in the barrel, where the gelation time depends on the concentration as well. In order to extrude Matrigel, it is necessary to possess a temperature-controlled bioprinting system (as presented in Figure 3D2) to retain the hydrogel at $4^{\circ} \mathrm{C}$. Otherwise, the dispensing needle clogs and makes bioprinting very challenging. In the literature, the bioprinting of Matrigel demonstrated high viability of human epithelial cells [39]. Furthermore, 3D bioprinted bone marrow stromal cells in Matrigel showed higher survival rate than those in alginate or agarose hydrogels, up to 7 days 
[136]. Multicellular constructs were also extruded and implanted for bone regeneration, and vascularization by the host tissue was demonstrated 2 weeks after implantation [137].

Methylcellulose (MC), a chemical compound derived from cellulose, is a semi flexible linear chain of polysaccharide and has the simplest chemical composition among cellulose products [138]. It is a thermosensitive and thermoreversible hydrogel, with sol-gel transition depending on polymer concentration, molecular weight and dissolved salt [139]. The aqueous MC solution used for cell culture is capable of gelling below $37^{\circ} \mathrm{C}$ [140]. A derivative of $\mathrm{MC}$, silanized hydroxypropyl methylcellulose hydrogel, has been patented due to $\mathrm{pH}$-sensitive properties and used for 3D osteogenic and chondrogenic cultures [141,142]. Methylocellulose is bioprintable, although it requires an additional apparatus as demanded by other thermosensitive and thermoreversible hydrogels, including a thermally controlled nozzle system (as presented in Fig. 3D2) and a heating plate. Methylocellulose is not appropriate for long-term culturing of cells. It presents unstable character with partial degradation immediately after being exposed to cell culture media [140]. Methylocellulose with bioactive glass was 3D printed with tremendous mechanical strength and can be an exceptional candidate for bone regeneration [143]. Recently, EBB was used to print nanofibrillated cellulose blended with alginate and loaded with chondrocytes [144]. In addition to EBB uses, methylcellulose was demonstrated as a scaffold matrix in the fabrication of spheroids made of corneal stromal cells cultured in a serum-free medium under a static and rotary cell culture system that can be used for further bioprinting applications [145].

Fibrin has been widely used in tissue engineering due to its inherent cell-adhesion capabilities and high cell seeding density $[26,146,147]$. It has simple gelation properties via 
directly combining fibrinogen, $\mathrm{Ca}^{2+}$ and thrombin in room temperature. Its polymerization conditions might be optimized depending on cell spreading properties or desired stiffness ranges, which is manipulated by concentration adjustment. Despite its great biological properties, fibrin has some limitations, such as a rapid degradation rate and limited mechanical stiffness. Fast and irreversible gelation causes difficulties during the extrusion process, which does not facilitate stable structures after extrusion [62]. There are a few methods applied in EBB. First of all, two components of fibrin (fibrinogen and thrombin) are very suitable for inkjet printing when printed separately $[148,149]$ and theoretically can be extruded as well. In the second approach, fibrinogen and thrombin can be mixed on ice preventing gelation and then extruded using a configuration presented in Fig. 3D2. The third method is using a multichamber, single-nozzle apparatus that blends both fibrinogen and thrombin into one solution at the very end of the extrusion process [71] as shown in Fig. 3E. In the fourth method, fibrinogen can be blended with another hydrogel, extruded in a desirable pathway and then crosslinked with thrombin [150]. Fibrin also has great potential in in situ bioprinting applications [151] because printed fibrinogen can rapidly crosslink with naturally occurring thrombin in situ.

In addition to bioprinting a single type of hydrogel, the multi-chamber, single-nozzle configuration shown in Fig. $3 \mathrm{E}$ has been used to blend and print multiple hydrogels or the same hydrogels with different material properties to generate heterogeneity in extruded fibers with varying properties of the material along the longitudinal direction of filaments [152]. Using a nozzle assembly shown in Fig. 3E, biofabrication of hybrid tissue-engineered porous scaffolds have been demonstrated, where multiple functional properties can be obtained by changing biomaterial type and concentration spatially [153]. Material flow and concentration through 
the mixture chamber can be controlled by regulating positive nozzle pressures. A similar approach was extended to triple chambers in a recent report [154], where scaffolds were fabricated by bending materials, chitosan, sodium alginate and chitin powder using a static mixer nozzle mounted on a 6-axis robotic printer.

Hydrogels in general lack the suitable biomimicry for the bioprinted cell phenotype, while each hydrogel does not include all the proteins existing in the corresponding cell-specific ECM. In addition, loading cells in high cell-density ranges close to those of natural tissues is challenging. In general, the higher the cell density, the better the cells interact and form the tissue [155]. Cell-to-cell interactions are not just lessened due to limited cell density; the microstructural environment of the hydrogels does not allow cells to interact efficiently. Hydrogels such as gelatin and collagen or RGD peptides have fibrous microstructural environments that allow cells to spread easily. However, other hydrogels do not possess this feature, and cells in general do not spread and do remain rounded. Concentrations of hydrogels also trigger this issue, creating a trade-off conflict between biological and mechanical properties. The higher the concentration of hydrogels, the lower the mobility of the cells in them and the higher the mechanical properties. Mechanical properties, on the other hand, are required to preserve the printed cell-laden scaffold intact. Some gels such as Pluronic F-127 can preserve their integrity when they are cultured in bulk; however, they cannot preserve their mechanical integrity when printed in filaments, and they dissolve in culture media quickly. Thus, strong gelation is needed before culturing cells in hydrogels. Rheological properties of hydrogels also play crucial roles in the EBB process, while bioink suspension should overcome surface-tension-driven droplet formation and be drawn in the form of straight filaments. When 
hydrogels are used in low concentration in the bioink, their drawability in the form of a straight filament is limited because the bioink spreads very quickly. On the other hand, when they are loaded in very high concentration, their extrusion process is very challenging and needs a significant level of pressure. Although this seems to be feasible for the process, it harms the cells significantly due to increased shear stress.

Degradation of hydrogels and associated byproducts are other limitations in hydrogelbased bioinks. In general, hydrogels degrade very slowly in vitro compared to in vivo; thus, cells that are encapsulated in them cannot proliferate and deposit considerable amounts of ECM. On the other hand, if degradation time in vivo is too long, it causes a chronic inflammatory response. Also, hydrogels should be chosen carefully because the toxic byproducts of degradation can be harmful to cells. In summary, hydrogels must be matched with the type of regenerated tissue, and they should require support for cells until the completion of the tissue regeneration process. Time of degradation is different for every type of hydrogel. For example, Yu et al. injected alginate and fibrin into rats [156]. After five weeks, alginate was still identified, whereas fibrin was reabsorbed.

Table 1 summarizes the hydrogels used in EBB, including the cell types used, their crosslinking mechanisms, the reversibility of their physical state, their extrusion mechanisms, their advantages and disadvantages and the sample tissue constructs that were bioprinted using EBB.

\subsection{Micro-carriers}

Recently, micro-carriers (Fig. 2B) have been used as reinforcement blocks in the EBB process. Cells can be loaded into small carriers in different geometries (spherical in general 
[157]) with porous architecture. Commercially available micro-carriers for bone and cartilage regeneration are made with dextran [158,159], plastic [160,161], glass [158], gelatin $[63,162]$ and collagen $[163,164]$. When cells are cultured on them, they allow cells to quickly proliferate. Maturated micro-carriers can be printed in a delivery medium such as hydrogels, as shown in Fig. 3F. One of the previously described hydrogel crosslinking mechanisms can be used during bioprinting of micro-carriers. It was demonstrated in a recent article that cells can have better interaction and aggregation inside the micro-carriers than the cells loaded in the hydrogel solution alone [63].

Micro-carriers have great potential in the scale-up tissue printing process using hard polymers. In general, hard polymers are not convenient for encapsulating cells due to limited diffusion; however, making porous micro-carriers and loading cells and allowing them to proliferate in them would be a great approach to assembling these carriers in 3D for hard-tissue scaffolding applications such as bone or cartilage. Although they can be considered an intermediate stage between hydrogels and cell aggregates, micro-carriers still have some challenges associated with them. The major limitations of this technique are how to deliver them successfully to the bioprinting stage and how to assemble them in 3D. In general, hydrogels are used as delivering mediums as in the tissue spheroid case, but ensuring contact between micro-carriers is very difficult. Other limitations are degradation of the micro-carrier material and associated end products that can be toxic to cells, and risks of clogging of nozzle tip due to the hard and adhesive nature of the micro-carriers, which can trigger their aggregation inside the nozzle tip. 


\subsection{Cell Aggregates}

Scaffold-free cell aggregates have been considered a promising direction in bioprinting because they enable building tissues in a relatively short period of time compared to the commonly used cell-laden hydrogel approach. Instead of expecting cells to proliferate in hydrogels, one can start with extremely high cell numbers, triggering them to deposit ECM in a confined space per demand, such as cylinder, torus, spheroids and honeycomb $[19,37,165]$. The hydrogel-free nature of the biomaterial facilitates quick maturation of building blocks, and the technology has demonstrated fabrication of cardiac patches $[166,167]$, blood vessels $[21]$ and nerve tissues [68]. Several biofabrication approaches have been investigated in the literature for cell aggregates, particularly tissue spheroids. These methods include the hanging drop, pellet (re-aggregation) culture or conical tube, micro-molded (non-adhesive) hydrogels, microfluidics (hydrodynamic cell trapping), liquid overlay, spinner flask and rotating wall vessel techniques [168]. It should be noted that not all of them have been applied in fabricating spheroids for bioprinting purposes, but any of them can be considered as an alternative approach as long as the technique facilitates efficient and economical generation of spheroids for scale-up tissue-printing activities. Not just homocellular, but also heterocellular, examples have been demonstrated [169-171]. Despite their great advantages, tissue spheroids have several challenges during the EBB process. First of all, loading tissue spheroids into the nozzle, which is generally a pipette [20] (see Fig. 3G1), is quite difficult. Tissue spheroids need a delivering medium to be extruded; in this case, the delivering medium is a fugitive ink such as a thermo-sensitive hydrogel that is inert to cell adhesion. In addition, tissue spheroids have quick fusion capabilities that trigger their aggregation inside the nozzle tip and make their printability 
very challenging. Upon printing, there is also a risk that tissue spheroids may not contact each other tightly enough. This generates a gap between spheroids, and the resulting tissue will be leaky. Last, and the most important, fabricating a huge number of tissue spheroids and bioprinting them in an automated way for long bioprinting missions is another hurdle to be faced when considering the transition of the technology to scale-up tissue fabrication in the near future. Despite these challenges, bioprinting tissue spheroids has been an exemplary means to rapidly create tissues in vitro, and further modifications have been made to the technology. Instead of delivering cells in high density in aggregated mature spheroid form, delivering them directly in pellet form works more efficiently [155], as shown in Fig. 3G2. In that case, bioprinting cells into printed micro-molds is essential to confine cells inside the molds and trigger them to aggregate in the shape of the molds [172]. Thus, two materials need to be deposited into the construct, where a cell pellet can be printed inside hydrogels that are inert to cell adhesion, such as agarose or alginate. There is a controversy among some scientists about whether or not the applied molding approach should be considered a scaffold. Although the mold itself supports the tissue to grow and mature, cells do not use the mold matrix to proliferate through; thus, the applied mold can be considered as a support structure, which is very common in traditional additive manufacturing technologies [22] used for supporting overhangs. The major hurdle with this approach is the difficulty of making large-scale tissues without using a temporary molding material. Thus, tissue strands [173] (Fig. 3G3) can be considered as an alternative approach, where long strands of tissues can be fabricated and printed using a custom-made nozzle apparatus. In this case, the laborious nature of the spheroid preparation and loading can be eliminated, and the need for printing an enclosure 
mold can be eliminated for cell pellets. Although this approach provides the unique advantage of printing tissue strands in tandem with vasculature, increasing the size of the tissue strands or the need for neo-capillarization in them can be considered milestones on the way to generating larger-scale tissues and organs in the future $[29,69]$. Despite the great advantages of the scaffold-free approach, the majority of the research community prefers hydrogel-based bioink due to its simplicity, abundance, scalability, affordability and ease of bioprintability, as well as the fact that there is no need for huge cell numbers to start with.

Cell-aggregate-based bioinks have great advantages, such as better cellular interactions, including homocellular and heterocellular interactions; close biomimicry; quick tissue formation; and long-term stability of cell phenotypes in 3D [155]. Despite these advantages, they have several limitations. First of all, a very high number of cells is needed to prepare a sufficient amount of aggregates. These numbers can go up to a few hundred million cells depending on the cell size and how quickly they deposit ECM. In general, expanding cells in these numbers is labor-intensive and costly, and some cell types cannot grow quickly, which limits their applicability and availability. In addition, parenchymal cells in highly metabolic organs do not secrete many ECM components, and the resulting cell aggregates are very weak in mechanical and structural integrity [174]. Therefore, stromal cells should be cocultured to provide enough strength for bioprinting uses. In addition to mechanical properties, the dimensional constraints are another hurdle. In general, the permeability of cell aggregates is smaller than that of hydrogels, and the diffusion of media and oxygen is highly limited. Thus, fabrication of spherical aggregates over $400 \mu \mathrm{m}$ can induce hypoxia, which is hard for highly metabolic cells to survive [175]. Resilient cells (i.e., stromal cells) or cells that like hypoxia (i.e., 
chondrocyte) can surpass these limitations. One of the naturally occurring spheroids in the human body is the lymph node. This tissue comprises stromal cells such as endothelial cells, fibroblasts and follicular dendritic cells, which provide physiological functionality in tissue ranging from a few millimeters to $1-2 \mathrm{~cm}$ long [176]. Thus, neocapillarization inside the cell aggregates is highly desired for scale-up fabrication of tissues and organs. Ehsan et al. presented vascularized tumor spheroids [26]. Early stages of tumor progression were investigated, and their work stands as a great example of a vascularized three-dimensional in vitro tissue model, which can be used for creating other organoids. From a bioprinting standpoint, bioprinting cell aggregates is very trivial when the cell pellet is loaded in the preaggregated state (Fig. 3G2) while the bioink can be printed like a hydrogel-based bioink without need for any other means. In that case, a supporting mold structure is needed for cells to aggregate. The mold structure should be printed with a minimum mold cavity; otherwise, cell pellets do not form aggregates, but rather remain a cell suspension [177]. For scale-up tissue printing missions, the need for molding is thus not ideal. When cell aggregates are loaded in mature form such as tissue spheroids or strands (Fig. 3G1), printing is not trivial while the bioink (in solid state) should be transferred to the printing stage with minimum stress on the cells. Thus, hydrogels or biological oil can be used as a medium to deliver them on the bioprinting stage; however, such a medium brings an issue when it needs to be washed out from the printed construct. In general, cell aggregates need to be printed before they become fully maturated, such as in the first 10 days of cell aggregation. Otherwise, maturated cell aggregates lose their ability to fuse. 


\subsection{Decellularized Matrix Components}

In addition to recent advances in hydrogel-free approaches, the extracellular matrix that is derived from nature's own scaffold has been considered as a new bioink source for advanced tissue fabrication. Taylor's groundbreaking work in organ decellularization [178] has attracted numerous researchers in the last five years in the regeneration of organs such as the heart [179], kidney [180], liver [181], cartilage and bone [182], pancreas [183] and others [7,184]. This later inspired Dong-Woo and his coworkers [64] to use decellularized matrix (dECM) components in printing tissue analogues. In their recent study, they decellularized tissues and chopped them into smaller fragments, which were then loaded with cells and printed with a PCL frame to support the tissue analogues. The process is illustrated in Fig. $3 \mathrm{H}$. Three different cells types, including hASCs, human inferior turbinate-tissue derived mesenchymal stromal cells (hTMSCs) and rat myoblast cells, have been tested using the proposed technology and demonstrated the natural differentiation of cells when they were loaded in their native dECM.

The approach seems to have a great benefit for biomimetic tissue and organ printing when the dECM bioink compounds can be tuned in a way that allows them to be printed with enhanced mechanical properties without the need for a polymer frame for future studies [51]. Decellularization matrix components, on the other hand, have limitations associated with the maturity state of the technology. Since dECM-based bioink has not yet been well established, there are some limitations related to the need for protocols and the low abundancy and the affordability of the bioink. Since the dECM is obtained from the decellularization of the natural organs and tissues, and the resultant $\mathrm{dECM}$ is tiny when the deceullarized $\mathrm{dECM}$ is crushed into small pieces, a very large volume of initial tissues or organs is needed to create scale-up tissues 
after bioprinting. In addition, dECM loses its mechanical and structural integrity as well as some biochemical properties when it is crushed into very small fragments. Furthermore, some toxic residuals can still stay in the crushed dECM components. Due to these issues, printed bioink cannot facilitate cell formation while cells can absorb the matrix components or the matrix shrinks significantly. Since the mechanical properties are very weak, there is a need for a frame printed using a hard material to keep the dECM structure without letting it collapse.

\section{Extrusion-based Bioprinters}

The first EBB technology, 3D plotting of thermo-reversible gels in a liquid medium, was reported by Muelhaupt's group at Freiburg Materials Research Center in the early 2000s [120]. The technology, named bioplotter, was later commercialized by EnvisionTec as 3D-Bioplotter ${ }^{\circledR}$. Since then, a number of extrusion-based bioprinters have been demonstrated by several research groups; some of them have been commercialized. The ideal bioprinter has specific system requirements, which include high resolution and accuracy, high-degree-of-freedom motion capability and motion speed, the ability to dispense various biomaterials simultaneously, user-friendliness, compactness, full-automation capability, sterilibility, affordability and versatility [41]. Several extrusion-based bioprinters have been developed in the literature. Some notable ones include a 3D printer with three heads enabling bioprinting of blood vessels and cardiac tissue constructs, developed by Forgacs and his coworkers [185], the Palmetto printer with the capability to dispense tissue spheroids, developed by Medical University of South Carolina (MUSC) and Clemson University [77], a multi-head tissue/organ building system (MtoBS) possessing six dispensing heads to fabricate heterocellular tissue 
constructs (i.e., osteochondral tissue), developed by Jin et al. [186], and a Multi-Arm BioPrinter [80] enabling bioprinting of hybrid constructs (scaffold-based and scaffold-free bioink materials) using independent robot arms in tandem.

Until 2005, 3D printers, in general, were expensive, proprietary and in industrial scale, and their high cost and closed nature limited the accessibility of the technology to researchers. With the invention of the Fab@Home printer [187], the first open-source low-cost printer was available to the public with versatile and multi-material printing capabilities that accelerated technology innovation and its migration into the bioprinting space. The emergence of commercially available bioprinters is probably one of the most remarkable developments of the past decade. Examples of those commercially available are the NovoGen MMX Bioprinter ${ }^{\mathrm{TM}}$, BioBots, the 3D Bioplotter ${ }^{\oplus}$, Bioassembly Tool, Fab@ Home and Biofactory [188]. The reader is referred to Table 2 for a detailed list of both non-commercial and commercial extrusion-based bioprinters used in various tissue and organ construct printing applications.

\section{Towards Vascularized Scale-up Tissue Fabrication}

Although several studies have been performed in EBB, printing vascularized, metabolically highly active thick tissues such as cardiac, pancreas, lung or liver tissues is still a challenge. In order to bioprint vascularized thick tissues, robust technologies and protocols should be developed to enable bioprinting of vascular constructs in multiple scales. Since it is very difficult to print capillaries at the submicron scale using the current technology, one alternative strategy can be bioprinting the macro-vasculature and expecting the capillaries to be formed by nature. Two alternative approaches have been considered in the literature: indirect bioprinting by utilizing a fugitive ink that is removed by thermally induced 
decrosslinking, leaving a vascular network behind [27,189], and direct bioprinting of a vasculature network $[21,86,190-192]$.

In the last couple years, several researchers have attempted to use a fugitive bioink to create vascular channels. These researchers include Khademhosseini's group $[25,61,193]$ (Fig. 4A1-A2), Dai's group [194,195] (Fig. 4B1-B2), Lewis and her coworkers [27,132] (Fig. 4C), and Chen's group [196] In these studies, cell-laden hydrogels were used as the base material to fabricate the tissue construct. Integrating the vascular network demonstrated increased cell viability inside the construct; even regions near channels exhibited significant differences when compared to regions away from the channels (Fig. 4A2). Although the majority of them attempted to create a vascular network in macro-scale and generate an endothelium lining inside the lumen via colonizing endothelial cells through perfusion, Dai et al. took a step forward and successfully achieved angiogenesis by sprouting endothelial cells within a fibrin network loaded with other supporting cells [197] (Fig. 4B1). Their study demonstrated that creating a vascular channel with a lumen surface covered with endothelial cells improved the diffusion of plasma protein and dextran molecule. Similar angiogenesis has already been developed in lab-on-a-chip models, where several supporting cells have been attempted and used in cancer metastasis studies led by Kamm's and George's groups $[198,199]$. Despite the great flexibility in bioprinting channels and the ability to create angiogenesis, this technology still faces several challenges. Another way of bioprinting a vascular network is by using a coaxial nozzle apparatus. A coaxial nozzle allows direct bioprinting of the vasculature with immediate crosslinking of hydrogel bioink, generating a smooth and continuous lumen in any desired length $[85,190]$. The anatomy can be controlled by controlling the bioprinting parameters, and 
the shape of the vascular network can be mediated by bioprinting. The vasculature can be loaded with cells such as fibroblast and smooth muscle cells, and can be embedded in a large tissue construct during bioprinting (Fig. 4D1-D2) [190]. Embedding vascular channels in hydrogel constructs thus increases viability of cells compare to viability of cells in bulk hydrogels. In addition to direct bioprinting of vasculatures, bioprinting of biologically recapitulated vascular network has been performed using tissue spheroids as building blocks as shown in Fig. 4E1 [21]. Six days after deposition, tissue spheroids completely fused and maturated into a vascular tissue demonstrating the self-assembly ability of tissue spheroids. In a recent work, this ability was further advanced into a perfusable hybrid tissue construct, where bioprinting of vasculature was integrated with tissue strands [29], where fibroblast tissue strands quickly fused to each other, maturated and formed the tissue around the vasculature (see Fig. 4F).

\section{Limitations and Challenges}

Extrusion-based bioprinting systems is the most convenient technique for rapidly fabricating 3-D porous cellular structures [200]. Although this technology lays the foundation for cell patterning for scale-up tissue and organ fabrication technologies, it has several limitations, including low resolution, shear-stress-induced cell deformation and limited material selection due to the need for rapid encapsulation of cells via gelation. Shear stress on the nozzle tip wall induces a significant drop in the number of living cells when the cell density or the bioink concentration is high. Yin et al. demonstrated that the bioprinting process could induce quantifiable cell death due to changes in dispensing pressure, nozzle geometry and bioink concentration [201]. Therefore, using optimum process parameters such as such as 
bioink concentration, nozzle pressure (ideally minimum), nozzle diameter and loaded cell density, one can overcome these limitations and challenges to some extent.

Restricted bioink selection and low resolution and accuracy limits applicability of EBB systems [41]. In addition, sufficiently high viscosity is essential for the bioink suspension to overcome surface-tension-driven droplet formation and be drawn in the form of straight filaments. High viscosity, on the other hand, triggers clogging inside the nozzle tip and should be optimized considering the diameter of the nozzle tip. In addition, nozzle clogging is one of the most common problems faced in EBB, and the bioink solidifies inside the nozzle tip for several reasons, such as imprecise adjustment of the temperature on the heating chamber (for thermally crosslinked bioink), splashing/diffusion of the crosslinker solution into the nozzle (for ionically crosslinked bioink), early fusion of spheroids before extrusion (for tissue spheroidbased bioink), coagulation of the bioparticles loaded in the bioink in relatively small inner nozzle diameter (for micro-carriers), discontinuity in the pressure overholding the bioink inside the nozzle tip and non-uniform bioink solutions with large fragments stacking the nozzle opening.

Bioprintable biomaterials constitute a very small percentage of the biomaterials used in tissue engineering. When designing and processing new biomaterials, the majority of biomaterials researchers do not consider bioprinting as an end application. Despite the great progress in last decade, bioprintable biomaterials or bioinks have several limitations associated with their biological, immunological, micro-structural, mechanical, rheological and chemical properties as discussed in details in Section 3. 
In addition to the abovementioned limitations, EBB faces hardware-related challenges. Pneumatically driven EBB systems require sterilization of the used air from the air dispenser compressor. Thus, using a filter on the airway would be ideal to minimize contamination of the printed structures. Sterilization of a mechanically driven system is more trivial while the mechanical dispenser head can be easily autoclaved. Mechanically driven systems are affordable, easy to program, portable, and do not need an air compressor unit and accessories. Pneumatically driven systems are very precise and accurate; a micro droplet size of $0.5 \mathrm{~nL}$ [202] can be generated using a valve-based system. However, the cost of the system increases as the precision of the deposition volume increases. A mechanically driven system necessitates a tighter tolerance selection on the ram and the nozzle unit. An incorrect selection during bioprinter head development results in an unnecessary power requirement on the motor, additional friction forces, leakage of bioink or failure of the nozzle assembly due to overloading. Mechanically driven systems provide a better printing ability for semi-solid or solid bioink such as cell aggregates. Pneumatically driven systems do not generate smooth extrusion of the semisolid or solid bioink and require another liquid or gel medium to deliver the bioink through the nozzle tip. Otherwise, the bioink can easily attach on the wall of the nozzle. No issues are foreseeable for gel-based bioprinting due to its liquid nature because liquids can easily transmit the force equally in all directions without any entrapment inside the nozzle. One of the most important aspects of nozzle selection is the friction coefficient on the wall of the nozzle tip because the friction coefficient mediates the shear stress, which might be detrimental for cells. Thus, a surface with a small friction coefficient and one that is easy to sterilize would be ideal for printing cells, e.g., glass pipettes [203]. Solenoid-based micro-extrusion enables dispensing 
of a sub- $\mu \mathrm{L}$ range volume of bioink [204] and is convenient for bioprinting of low-viscosity bioink materials with an ionic- or UV-irradiation-based crosslinking mechanism. Although high accuracy can be obtained, a number of factors affect the accuracy and reproducibility of solenoid-based micro-extrusion systems, including the time lapse between actuation time (where the coil is energized) and the time when the valve opens; the soft nature of the seal between the plunger and the valve seat, resulting in compression of the sealing and time delays; and the need for high actuating pressure to dispense highly viscous bioink. In addition, temperature, and hence viscosity, variations considerably affect the valve opening time when the bioink has to be displaced for moving the plunger. Therefore, solenoid-based microextrusion systems may not be convenient for thermally controlled nozzle configurations. In addition, fabrication of tolerances on the nozzle is important. For each different dispensing tip mounted, calibration of the valve may be needed, especially for very long dispensing tips.

\section{Future Perspective}

Extrusion-based bioprinting stands as a promising technique among bioprinting technologies due to its versatility in printing various bioink types; its capability in printing porous tissue analogues for enhanced media diffusion and perfusion capabilities; and its ability to print fully biological, large tissue constructs rapidly and with acceptable mechanical and biological properties, which cannot be achieved using other bioprinting techniques, including laser-based and droplet-based bioprinting. Despite the great progress and remarkable achievements of the last decade, there is still much more to be investigated to generate robust and viable end-products for applications such as pharmaceutics, transplantation and clinics [205]. The trends listed below can be considered under future perspectives in EBB technology. 


\subsection{In Situ Bioprinting}

Bioprinting living tissue constructs or cell-laden scaffolds in vitro has been well studied in the literature. Success has been achieved with growing tissues in laboratory settings, e.g., thin tissues or tissues that do not need vascularization, including skin [206] and cartilage [30]. In situ bioprinting, on the other hand, can enable growth of thick tissues in critical defects with the help of vascularization driven by nature in the body. Therefore, in situ bioprinting is a promising direction for bioprinting porous tissue analogues that can engraft with the endogenous tissue and generate new tissue along with vascularization through recruitment of endothelial cells into the tissue construct and sprouting of capillaries from the endogenous tissue.

Very few attempts have been made in in situ bioprinting; only inkjet-based bioprinting $[207,208]$ and laser-based bioprinting [209] have been considered in limited capacity. Extrusionbased bioprinting, on the other hand, has the flexibility and capability to bioprint tissue analogues with controlled porous architecture. In order to take the EBB into a robust state in situ, bioprinting ex vivo on explants (see Fig. 5A) can be considered as a transitional stage, where explants can be harvested from the animal model, and the tissue construct can be built and engineered inside the defect. When the defect model is still alive, it allows cells of native tissue to migrate and grow through the printed tissue construct or vice versa. Although bioprinting into an explant model has been performed using inkjet-based bioprinting [210], it has not been attempted using EBB so far except for a preliminary effort on printing into a defect on a non-living femur model placed on a fixture, which was then filled with precrosslinked sodium alginate [73]. The major advantage of printing into ex vivo defect models is 
that it provides a translational step towards in situ bioprinting on a live animal model (see Fig. 5B), which one day will bring the bioprinter technologies from benchside to bedside. In situ bioprinting, on the other hand, seems to be very promising in developing tissue analogues directly on the defect model in operating rooms, which will pave the way to develop associated enabling technologies for humans in the future (see Fig. 5C). It can be envisioned that in situ bioprinting into the defect on live models with controlled porosity can be used for several purposes, such as deep dermal injuries, composite tissues and flaps, and calvarial or craniofacial defects during maxillofacial or brain surgeries.

\subsection{Investigating New Bioink Materials}

Although great progress has been made with novel biomaterials and biomaterial processing techniques, the development of bioinks that are well suited for EBB and allow one to bioprint mechanically and biologically enhanced tissue constructs is still a great need. Particularly, new biomaterials with very quick gelation or solidification capabilities providing a mild environment for cells would be highly desirable. Despite the great success in developing new hydrogels for tissue engineering, not all of them have been adopted to bioprinting. Thus, a new field of study such as "bioprintable biomaterials" under the biomaterials and biofabrication fields could be a great leap to promote research in this direction.

One of the major limitations in currently available hydrogel-based bioinks is the lack of environment for promoting differentiation and growth of stem cells into multiple lineages [211]. While tissues and organs comprise multiple cell types organized spatially, a bioink that 
supports organization of the heterocellular nature of the tissue microstructure should be developed. Although cells in hydrogels can migrate and proliferate to some extent, the majority of the currently used hydrogels in bioprinting are biomaterials with adherent properties for cell attachment [45]. Therefore, hydrogels that have natural fibers, such as collagen and RGD peptides, can be reinforced to further improve biological characteristics. One of the tools for controlling cell behavior could be nanocomposite hydrogels, which can control stem-cell differentiation spatially and temporally [212]. By combining chemical, mechanical and physical stimuli, the native tissue structure and physical properties can be mimicked. The cellular response should amplify and modify the differentiation status of stem cells [212]. In general, highly novel hydrogels should be developed to do the following: promote cell adhesion, proliferation, aggregation and differentiation toward multiple lineages; exhibit high mechanical integrity and structural stability without dissolving after bioprinting; facilitate engraftment with the endogenous tissue without generating immune response; demonstrate bioprintability with ease of shear thinning, rapid solidification and formability; and be affordable, abundant and commercially available with appropriate regulatory guidelines for clinical use.

Polymer-free bioprinting is one of the most exciting directions in tissue printing. It enables rapid fabrication of tissues and overcomes all the drawbacks associated with polymers, such as degradation and related toxic products, limited cell infiltration and encapsulation capability, poor cell migration and proliferation inside the polymer matrix, and a smaller chance of vascularization. Despite the great advantages, mechanical properties are the major drawback, and careful investigation should be conducted to achieve acceptable mechanical rigidity before and after the bioprinting process. In general, culturing cell aggregates for a 
longer period of time generates better mechanical properties because cells deposit more ECM, particularly elastin and collagen proteins; however, their fusion and adhesion capabilities decrease while maturation is completed. Thus, cells need to be guided biologically to deposit satisfactory collagen and elastin in a shorter period of time to provide mechanical strength; these are the major proteins in the connective tissue stromal of parenchymal organs. Better mechanical coherency also helps the operator to load the bioink easily without any challenges; however, aggregation time should be optimized to facilitate quick fusion capabilities after bioprinting. In this regard, novel nozzle configurations should be developed that enable the loading and printing of polymer-free bioink with minimum structural damage, preserving their integrity.

\subsection{EBB-mediated Gene Therapy}

To date, both in vivo and ex vivo gene therapy have been used in tissue repair [213]; however, bioprinting genes have been studied to a limited extent [67]. While differentiating stem cells into multiple lineages is crucial in order to recapitulate the tissue biology, bioprinting genes spatially could potentially overcome this limitation and could allow transduction and differentiation of autologous cells into multiple lineages per demand spatially. In addition to bioprinting-mediated ex vivo gene therapy, bioprinting-mediated in vivo gene therapy can also be used and is very appealing because it is technically feasible and will be very effective in the operating room. Bioprinting genes for locally controlled gene therapy can surpass the limitations of currently available methods, including direct injection or gene-activated matrices such as potential spreading of genes to non-target sites [214]. Although naked plasmid DNA 
(pDNA) can be applied for gene delivery, it typically results in low transfection efficiency and high toxicity [215], therefore loading pDNA in biodegradable microparticles has recently generated promising results for controlled gene delivery. In this regard, bioprinting will not only allow spatial control over gene therapy but also enable slow release of the gene vector to the surrounding cells or tissues. By bioprinting tissue constructs ex vivo or in vivo, one can engineer the gene therapy through the sustained and controlled release of genes loaded in microparticles. This way, new delivery systems can be developed with controlled, localized and sustained release of genes with high efficiency and low toxicity, and the release profile can be mediated by altering bioprinting parameters and releasing multiple genes sequentially and spatiotemporally. This is particularly important for tissue systems with functionality-graded tissue heterogeneity, such as osteochondral tissues with multiple osteal and chondral regions interfacing at a unique zone with extremely unique tissue anatomy. Thus, gene release systems can efficiently generate such zonal differentiation gradually.

\subsection{Bioprinting Scale-up Tissues and Organs}

In vitro fabrication of physiologically relevant tissues is a very sophisticated phenomenon comprising a hierarchical arrangement of multiple cell types, including a multiscale network of vasculature in stroma and parenchyma, along with lymphatic vessels and, occasionally, neural and muscle tissue, depending on the tissue type. In vitro engineered tissue models that incorporate all of these components are still far out on the horizon. The major roadblock to this ambitious goal is multi-scale vascularization [205]. As larger vasculatures can be bioprinted using EBB systems, controllable capillary network can be created by nature as already achieved in hydrogels $[198,199]$. Since the time-scale of neovascularization and the 
post-bioprinting maturation of tissue constructs is not the same, printed parenchymal cells require media and oxygen support immediately and therefore macrovascular network should be created with a diffusion distance of 200-300 $\mu \mathrm{m}$ [86] depending on the biomaterial and its interstitial flow capabilities. In addition, biomaterials with high micro-porosity should be preferred because they will overcome the abovementioned issues to some extent. Bioprinting technology offers a great benefit in the hierarchical arrangement of cells or building tissue blocks in a 3D microenvironment, but the bioink and the post-bioprinting maturation phase are as important as the bioprinting process itself. Although hydrogels such as fibrin and GelMA support neovascularization, they may not provide the ideal microenvironment and signaling for survival, motility and differentiation of a wide array of tissue-specific cells, and their stability over prolonged in vitro culture is weak $[216,217]$. Thus, tissue-specific cell types can be bioprinted in a scaffold-free spheroid form (i.e., pancreatic islets or lymphatic follicles) that is pre-vascularized and can be coated with a very thin layer of angiogenesis supporting biomaterial (i.e., fibrin). This can promote formation of contiguous vascular network within the spheroid along with elongation of sprouts into the scaffold encapsulating spheroids, which can even facilitate anastomosis of sprouted vessels between two spheroids. In addition, successful sprouting of these capillaries from spheroids to the macro-vascular network is also crucial to make a fully contiguous vascular network.

\subsection{Need for High-Resolution and Fully Automated Systems}

One of the major shortcomings of EBB is the lack of high-resolution systems due to the nature of the extrusion process itself. Although certain errors can be induced due to other system components, such as errors associated with the motion system or the extrusion process 
itself has an enormous contribution to the low resolution. Although very small nozzle tips can be considered possible, decreasing the nozzle size results in a considerable increase in the shear stress and corresponding cell damage and death. Thus, EBB systems should be modified to alleviate this issue. In addition, lowering the size further increases issues such as nozzle clogging and the need for elevated dispensing pressure levels. Although a low electric field can be applied to reduce the size of the printed filaments as widely used in electrohydrodynamic printing [53], cells should be kept away from the electric field to safely deliver them. A recent approach in the application of electrohydrodynamic jetting in inkjet-based bioprinting demonstrates the safe usage of the system with cells; this approach has the potential to be used in EBB [54]. The other potential of increasing the resolution is to use a cone-shaped nozzle (i.e., Taylor cone or regular cone) that has a relatively alleviated shear stress, which reaches its maximum at the end of the nozzle tip, affecting cells at a minimum duration [218]. In addition to these approaches, a highly innovative approach might be using a nozzle-free extrusion system that enables the bioink to overcome surface-tension-induced droplet formation.

\subsection{Bioprinting New Types of Organs}

In addition to bioprinting tissue and organ constructs to replace their existing counterparts, for a longer-term perspective, the authors also envision bioprinting new types of organs that do not exist in nature but can be engineered to perform specific and useful functions, such as treating diseases or enhancing the physiology of the human body beyond its ordinary capabilities. Such organs can be either fully biological or in the form of cyborg organs interweaving electronics and biology. A recent work [83] demonstrated a proof of concept of such a cyborg organ example. Bionic ears were printed using a hybrid approach via integration 
of bioprinting chondrocytes in alginate along with printed silver nanoparticles in the form of an inductive coil antenna. The cultured cyborg organ model was then tested and was found to exhibit enhanced auditory sensing for radio frequency reception (see Fig. 6). Three-dimensional printing in that study demonstrated the proof of concept for cyborg ears, promising a seamless integration of electronics and biology for future off-the-shelf cyborg organs. These organs can also be constructed fully biologically and even generate functions that the power system does in daily life, such as producing electricity. With recent advances in understanding the genomic basis of electric organs (EOs) [219], which exist in electric eels and produce electricity for communication, sensing, navigation, predation and defense, the possibility of fabricating similar models of EOs can be considered for future attempts in using such an organ for transplantation or for replacing batteries for pacemakers [174] or cochlear implants [220] or powering prosthetic devices.

\subsection{Regulatory Concerns}

Due to its unique capabilities, EBB has been preferred for fabrication of living tissues and organs, and regulatory issues seem to be down the way as the technology transforms into products for clinics and human-use purposes. Currently, there is no regulations that has been laid down for bioprinting including bioink, bioprinters and bioprinted products such as tissues, and FDA has not imposed any regulatory restrictions on bioprinting technology yet. Cuttingedge technologies such as bioprinting cannot be easily categorized for regulatory purposes while it does not fit into the general classification of "device", "drug" or "biologic" under FDA regulations. Office of Combination Products (OCP) formed by FDA can handle this situation, where "combination product" is defined in 21 CFR §3.2(e) as "A product comprised of two or 
more regulated components, i.e., drug/device, biologic/device, drug/biologic or drug/device/biologic, that are physically, chemically, or otherwise combined or mixed and produced as a single entity" [221]. The OCP does not conduct product reviews but assigns combination products to the appropriate FDA center (i.e., the Center for Drug Evaluation and Research (CDER), The Center for Biologics Evaluation and Research (CBER) and the Center for Devices and Radiological Health (CDRH)), ensures timely and effective premarket review and appropriate post market regulations, and serves as a resource to industry and the FDA center's review staff [221]. Ultimately, both the bioprinted tissues and the 3D bioprinter itself could be classified as combination products. The bioprinter is classifiable as a medical device as it is used for treating humans and is intended to affect the structure and function of the human body. The bioink can be classified as a biologic (cells) or a drug (genes, growth factors. etc.). The tissues printed by the bioprinter could be classified as a biologic. Currently, there are only few companies in the world [188]; however, with the increasing global interest and needs, more businesses will be established in the growing bioprinting market and success of the first technology going through FDA regulations will be exemplary for preceding technologies and products.

In addition to regulatory concerns with bioprinting, ethical concerns will be another fact to be considered for future attempts. Although, majority of the trial have been made on animals, ethical concerns will raise when printing tissues or organs for transplant to humans. Patients' own stems will be required to overcome rejection issues and patient may not be willing to allow their cells went through several procedures in order to 3D bioprint an organ such as mixing their cells with biomaterials obtained from animals. In addition to those, new 
types of organs can also be manipulated and organs for superior functionalities, which can mutant the human body or give some additional superiority to it such as energy generating organs or muscles that do not produce lactic acid and eliminates tireless nature of the body and give some extra competitiveness to the athletes during the competitions. This is not ethical and may not be likely to be accepted in the future. The religion and cultural norms may also play an important role in ethical concerns such as transplantation of patient own cells within a scaffold made from animal proteins will not be acceptable for some religious and cultural rules.

\section{Conclusion}

This review for the first time presents the recent advances in EBB systems and their components, including the technology, the bioink, process configurations, bioprinters and enabling technologies for vascularized tissue fabrication. Despite the great benefits and flexibility of printing a wide range of bioinks and advantages such as the ability to bioprint mechanically sound, structurally integrated, scale-up tissue constructs, the technology currently faces several limitations, particularly in the resolution of printed features, the ability to define anatomically correct shapes and the ability to generate scale-up tissue constructs. In addition to a discussion of recent progress in the field, the paper provides the reader with the limitations of the technology and outlines promising directions for new future prospects that will enable viable solutions for applications ranging from tissue engineering and pharmaceutics to clinical uses.

\section{Acknowledgement}

This work has been supported by National Science Foundation CMMI Awards 1349716 and 1462232, Diabetes in Action Research and Education Foundation and the Grow lowa Values 
Funds. We would like to thank Ms. Laura L. Hupp, associate attorney in Shook, Hardy \& Bacon L.L.P., for her insight on regulatory issues. We thank Melanie Laverman, Rebecca Barrett and Dr. Adil Akkouch from The University of lowa for improving the quality of the organization. The authors would like to express their gratitude to Dr. Christopher Barnatt (ExplainingTheFuture.com), Prof. J. Alblas (University Medical Center Utrecht), Prof. A. Khademhosseini (Harvard University), Prof. J. Hosek (Czech Technical University in Prague), Prof. W. Sun (Drexel University and Tsinghua University), Prof. J.A. Lewis (Harvard University), Prof. G.D. Prestwich (University of Utah), and Prof. M. Mc Alpine (Princeton University) in providing the high-quality images of some figures.

The authors confirm that there are no known conflicts of interest associated with this publication and there has been no significant financial support for this work that could have influenced its outcome.

\section{References}

[1] C. Abeykoon, P.J. Martin, A.L. Kelly, E.C. Brown, A review and evaluation of melt temperature sensors for polymer extrusion, Sensors Actuators, A Phys. 182 (2012) 1627. doi:10.1016/j.sna.2012.04.026.

[2] H. Lipson, M. Kurman, Fabricated: The New World of 3D Printing, Wiley, 2013.

[3] I. Zein, D.W. Hutmacher, K.C. Tan, S.H. Teoh, Fused deposition modeling of novel scaffold architectures for tissue engineering applications, Biomaterials. 23 (2002) 1169-1185. doi:10.1016/S0142-9612(01)00232-0.

[4] T.H. Ang, F.S.A. Sultana, D.W. Hutmacher, Y.S. Wong, J.Y.H. Fuh, X.M. Mo, et al., Fabrication of 3D chitosan-hydroxyapatite scaffolds using a robotic dispensing system, Mater. Sci. Eng. C. 20 (2002) 35-42. doi:http://dx.doi.org/10.1016/S09284931(02)00010-3. 
[5] D.W. Hutmacher, M. Sittinger, M. Risbud, Scaffold-based tissue engineering: rationale for computer-aided design and solid free-form fabrication systems, Trends Biotechnol. 22 (2004) 354-362. doi:http://dx.doi.org/10.1016/j.tibtech.2004.05.005.

[6] B. Rai, S.H. Teoh, D.W. Hutmacher, T. Cao, K.H. Ho, Novel PCL-based honeycomb scaffolds as drug delivery systems for rhBMP-2, Biomaterials. 26 (2005) 3739-3748. doi:http://dx.doi.org/10.1016/j.biomaterials.2004.09.052.

[7] S.J. Hollister, R.A. Levy, T.-M. Chu, J.W. Halloran, S.E. Feinberg, An image-based approach for designing and manufacturing craniofacial scaffolds, Int. J. Oral Maxillofac. Surg. 29 (2000) 66. doi:http://dx.doi.org/10.1016/S0901-5027(00)80128-9.

[8] C.Y. Lin, N. Kikuchi, S.J. Hollister, A novel method for biomaterial scaffold internal architecture design to match bone elastic properties with desired porosity, J. Biomech. 37 (2004) 623-636. doi:10.1016/j.jbiomech.2003.09.029.

[9] R.M. Schek, E.N. Wilke, S.J. Hollister, P.H. Krebsbach, Combined use of designed scaffolds and adenoviral gene therapy for skeletal tissue engineering, Biomaterials. 27 (2006) 1160-1166. doi:http://dx.doi.org/10.1016/j.biomaterials.2005.07.029.

[10] D.J. Odde, M.J. Renn, Laser-guided direct writing of living cells, Biotechnol. Bioeng. 67 (2000) 312.

[11] L. Pardo, W.C. Wilson, T. Boland, Characterization of Patterned Self-Assembled Monolayers and Protein Arrays Generated by the Ink-Jet Method, Langimur. (2003) 1462-1466.

[12] V. Mironov, T. Boland, T. Trusk, G. Forgacs, R.R. Markwald, Organ printing: computeraided jet-based 3D tissue engineering, Trends Biotechnol. 21 (2003) 157-161. doi:http://dx.doi.org/10.1016/S0167-7799(03)00033-7.

[13] F. Guillemot, V. Mironov, M. Nakamura, Bioprinting is coming of age: report from the International Conference on Bioprinting and Biofabrication in Bordeaux (3B'09), Biofabrication. 2 (2010) 010201. doi:10.1088/1758-5082/2/1/010201.

[14] A. Pfister, R. Landers, A. Laib, U. Hübner, R. Schmelzeisen, R. Mülhaupt, Biofunctional Rapid Prototyping for Tissue-Engineering Applications: 3D Bioplotting versus 3D Printing, J. Polym. Sci. Part A Polym. Chem. 42 (2004) 624-638. doi:10.1002/pola.10807. 
[15] S.W. Khalil Saif, Biopolymer deposition for freeform fabrication of hydrogel tissue constructs, Mater. Sci. Eng. C. 27 (2007) 469-478. doi:10.1016/j.msec.2006.05.023.

[16] S.W. Khalil S., Nam J., Multi-nozzle deposition for construction of 3-D biopolymer tissue scaffolds, Rapid Prototyp. J. 11 (2005) 9-17. DOI 10.1108/13552540510573347.

[17] I. Elloumi-Hannachi, M. Yamato, T. Okano, Cell sheet engineering: A unique nanotechnology for scaffold-free tissue reconstruction with clinical applications in regenerative medicine, J. Intern. Med. 267 (2010) 54-70. doi:10.1111/j.13652796.2009.02185.x.

[18] T. Boland, V. Mironov, A. Gutowska, E.A. Roth, R.R. Markwald, Cell and organ printing 2: Fusion of cell aggregates in three-dimensional gels, Anat. Rec. Part A Discov. Mol. Cell. Evol. Biol. 272A (2003) 497-502. doi:10.1002/ar.a.10059.

[19] K. Jakab, A. Neagu, V. Mironov, R.R. Markwald, G. Forgacs, Engineering biological structures of prescribed shape using self-assembling multicellular systems, Proc Natl Acad Sci U S A. 101 (2004) 2864-2869. doi:10.1073/pnas.0400164101.

[20] V. Mironov, R.P. Visconti, V. Kasyanov, G. Forgacs, C.J. Drake, R.R. Markwald, Organ printing: tissue spheroids as building blocks, Biomaterials. 30 (2009) 2164-74. doi:10.1016/j.biomaterials.2008.12.084.

[21] C. Norotte, F. Marga, L. Niklason, G. Forgacs, Scaffold-Free Vascular Tissue Engineering Using Bioprinting, Biomaterials. $30 \quad$ (2010) 5910-5917. doi:10.1016/j.biomaterials.2009.06.034.

[22] S. V Murphy, A. Atala, 3D bioprinting of tissues and organs, Nat Biotech. 32 (2014) 773785. doi:10.1038/nbt.2958.

[23] L. Horváth, Y. Umehara, C. Jud, F. Blank, A. Petri-Fink, B. Rothen-Rutishauser, Engineering an in vitro air-blood barrier by 3D bioprinting, Sci. Rep. 5 (2015) 7974. doi:10.1038/srep07974.

[24] C. Almeida, T. Serra, M. Oliveira, J. Planell, M. Barbosa, M. Navarro, Impact of 3-D printed PLA- and chitosan-based scaffolds on human monocyte/macrophage responses: 
unraveling the effect of 3-D structures on inflammation., Acta Biomater. 10 (2014) 61322. doi:10.1016/j.actbio.2013.10.035.

[25] L.E. Bertassoni, J.C. Cardoso, V. Manoharan, A.L. Cristino, N.S. Bhise, W. Araujo, et al., Direct-write bioprinting of cell-laden methacrylated gelatin hydrogels., Biofabrication. 6 (2014) 024105. doi:10.1088/1758-5082/6/2/024105.

[26] S.M. Ehsan, K.M. Welch-Reardon, M.L. Waterman, C.C.W. Hughes, S.C. George, A threedimensional in vitro model of tumor cell intravasation., Integr. Biol. (Camb). 6 (2014) 603-10. doi:10.1039/c3ib40170g.

[27] D. Kolesky, R. Truby, A.S. Gladman, T. Busbee, K. Homan, J. Lewis, Bioprinting: 3D Bioprinting of Vascularized, Heterogeneous Cell-Laden Tissue Constructs, Adv. Mater. 26 (2014) 2966. doi:10.1002/adma.201470124.

[28] F. Marga, K. Jakab, C. Khatiwala, B. Shepherd, S. Dorfman, B. Hubbard, et al., Toward engineering functional organ modules by additive manufacturing, Biofabrication. 4 (2012) 22001. http://stacks.iop.org/1758-5090/4/i=2/a=022001.

[29] Y. Yu, Y. Zhang, I.T. Ozbolat, A Hybrid Bioprinting Approach for Scale-Up Tissue Fabrication, J. Manuf. Sci. Eng. 136 (2014) 061013. doi:10.1115/1.4028511.

[30] W. Zhang, Q. Lian, D. Li, K. Wang, D. Hao, W. Bian, et al., Cartilage repair and subchondral bone migration using 3D printing osteochondral composites: a one-year-period study in rabbit trochlea., Biomed Res. Int. 2014 (2014) 746138. doi:10.1155/2014/746138.

[31] M.T. Poldervaart, H. Wang, J. van der Stok, H. Weinans, S.C.G. Leeuwenburgh, F.C. Öner, et al., Sustained release of BMP-2 in bioprinted alginate for osteogenicity in mice and rats., PLoS One. 8 (2013) e72610. doi:10.1371/journal.pone.0072610.

[32] W. Lee, J.C. Debasitis, V.K. Lee, J.H. Lee, K. Fischer, K. Edminster, et al., Multi-layered culture of human skin fibroblasts and keratinocytes through three-dimensional freeform fabrication, Biomaterials. 30 (2009) 1587-1595. doi:10.1016/j.biomaterials.2008.12.009.

[33] P. Godoy, N.J. Hewitt, U. Albrecht, M.E. Andersen, N. Ansari, S. Bhattacharya, et al., Recent advances in $2 \mathrm{D}$ and $3 \mathrm{D}$ in vitro systems using primary hepatocytes, alternative hepatocyte sources and non-parenchymal liver cells and their use in investigating mechanisms of hepatotoxicity, cell signaling and ADME., 2013. doi:10.1007/s00204-013- 
1078-5.

[34] R. Gaetani, P. Doevendans, C.H.G. Metz, J. Alblas, E. Messina, A. Giacomello, et al., Cardiac tissue engineering using tissue printing technology and human cardiac progenitor cells, Biomaterials. 33 (2012) 1782-1790. doi:10.1016/j.biomaterials.2011.11.003.

[35] C.L. Ventola, Medical Applications for 3D Printing: Current and Projected Uses, P\&T. 39 (2014) 704-711.

[36] T.Q. Huang, X. Qu, J. Liu, S. Chen, 3D printing of biomimetic microstructures for cancer cell migration, Biomed. Microdevices. 16 (2014) 127-132. doi:10.1007/s10544-013-98126.

[37] K. Jakab, C. Norotte, F. Marga, K. Murphy, G. Vunjak, G. Forgacs, Tissue engineering by self-assembly and bio-printing of living cells, Biofabrication. 2 (2010) 22001. http://stacks.iop.org/1758-5090/2/i=2/a=022001.

[38] L. Moroni, J.R. De Wijn, C.A. Van Blitterswijk, 3D fiber-deposited scaffolds for tissue engineering: Influence of pores geometry and architecture on dynamic mechanical properties, Biomaterials. 27 (2006) 974-985. doi:10.1016/j.biomaterials.2005.07.023.

[39] J.E. Snyder, Q. Hamid, C. Wang, R. Chang, K. Emami, H. Wu, et al., Bioprinting cell-laden matrigel for radioprotection study of liver by pro-drug conversion in a dual-tissue microfluidic chip., Biofabrication. 3 (2011) 034112. doi:10.1088/1758-5082/3/3/034112.

[40] J.D. Perkins, Are we reporting the same thing?: Comments, Liver Transplant. 13 (2007) 465-466. doi:10.1002/It.

[41] A.B. Dababneh, I.T. Ozbolat, Bioprinting Technology: A Current State-of-the-Art Review, J. Manuf. Sci. Eng. 136 (2014) 061016. doi:10.1115/1.4028512.

[42] F.P.W. Melchels, M.N. Domingos, T.J. Klein, J. Malda, P.J. Bartolo, D.W. Hutmacher, Additive manufacturing of tissues and organs, Prog. Polym. Sci. 37 (2012) 1079-1104. doi:10.1016/j.progpolymsci.2011.11.007.

[43] A. Khoda, I.T. Ozbolat, B. Koc, Engineered tissue scaffolds with variational porous architecture., J. Biomech. Eng. 133 (2011) 011001. doi:10.1115/1.4002933. 
[44] S.M. Giannitelli, D. Accoto, M. Trombetta, A. Rainer, Current trends in the design of scaffolds for computer-aided tissue engineering, Acta Biomater. 10 (2014) 580-594. doi:http://dx.doi.org/10.1016/j.actbio.2013.10.024.

[45] A. Skardal, J. Zhang, L. McCoard, X. Xu, S. Oottamasathien, G.D. Prestwich, Photocrosslinkable hyaluronan-gelatin hydrogels for two-step bioprinting., Tissue Eng. Part A. 16 (2010) 2675-85. doi:10.1089/ten.TEA.2009.0798.

[46] G. Fielding, A. Bandyopadhyay, S. Bose, Effects of silica and zinc oxide doping on mechanical and biological properties of 3D printed tricalcium phosphate tissue engineering scaffolds, Dent. Mater. 28 (2012) 113-122. doi:10.1016/j.dental.2011.09.010.

[47] J. Visser, B. Peters, T.J. Burger, J. Boomstra, W.J. Dhert, F.P.W. Melchels, et al., Biofabrication of multi-material anatomically shaped tissue constructs., Biofabrication. 5 (2013) 035007. doi:10.1088/1758-5082/5/3/035007.

[48] T. Billiet, E. Gevaert, T. De Schryver, M. Cornelissen, P. Dubruel, The 3D printing of gelatin methacrylamide cell-laden tissue-engineered constructs with high cell viability, Biomaterials. 35 (2014) 49-62. doi:10.1016/j.biomaterials.2013.09.078.

[49] N.G. Durmus, S. Tasoglu, U. Demirci, Bioprinting: Functional droplet networks., Nat. Mater. 12 (2013) 478-9. doi:10.1038/nmat3665.

[50] F.P.W. Melchels, W.J. Dhert, D.W. Hutmacher, J. Malda, Development and characterisation of a new bioink for additive tissue manufacturing, J. Mater. Chem. B. 2 (2014) 2282. doi:10.1039/c3tb21280g.

[51] F. Pati, D. Ha, J. Jang, H.H. Han, J. Rhie, D.-W. Cho, Biomimetic 3D tissue printing for soft tissue regeneration, Biomaterials. 62 (2015) 164-175. doi:10.1016/j.biomaterials.2015.05.043.

[52] T. Xu, W. Zhao, J.-M. Zhu, M.Z. Albanna, J.J. Yoo, A. Atala, Complex heterogeneous tissue constructs containing multiple cell types prepared by inkjet printing technology, Biomaterials. $34 \quad$ (2013) 130-139. doi:http://dx.doi.org/10.1016/j.biomaterials.2012.09.035. 
[53] L. Gasperini, D. Maniglio, A. Motta, C. Migliaresi, An electrohydrodynamic bioprinter for alginate hydrogels containing living cells., Tissue Eng. Part C. Methods. 21 (2015) 123-32. doi:10.1089/ten.TEC.2014.0149.

[54] P.A. Eagles, A.N. Qureshi, S.N. Jayasinghe, Electrohydrodynamic jetting of mouse neuronal cells., Biochem. J. 394 (2006) 375-8. doi:10.1042/BJ20051838.

[55] U. Demirci, G. Montesano, Single cell epitaxy by acoustic picolitre droplets., Lab Chip. 7 (2007) 1139-45. doi:10.1039/b704965j.

[56] H. Lin, D. Zhang, P.G. Alexander, G. Yang, J. Tan, A.W.-M. Cheng, et al., Application of visible light-based projection stereolithography for live cell-scaffold fabrication with designed architecture., Biomaterials. $34 \quad$ (2013) 331-9. doi:10.1016/j.biomaterials.2012.09.048.

[57] C. Mézel, A. Souquet, L. Hallo, F. Guillemot, Bioprinting by laser-induced forward transfer for tissue engineering applications: jet formation modeling., Biofabrication. 2 (2010) 014103. doi:10.1088/1758-5082/2/1/014103.

[58] A.N. Mehesz, J. Brown, Z. Hajdu, W. Beaver, J.V.L. da Silva, R.P. Visconti, et al., Scalable robotic biofabrication of tissue spheroids, Biofabrication. 3 (2011) 25002. http://stacks.iop.org/1758-5090/3/i=2/a=025002.

[59] J.H.Y. Chung, S. Naficy, Z. Yue, R. Kapsa, A. Quigley, S.E. Moulton, et al., Bio-ink properties and printability for extrusion printing living cells, Biomater. Sci. 1 (2013) 763. doi:10.1039/c3bm00012e.

[60] S. Khalil, W. Sun, Bioprinting endothelial cells with alginate for 3D tissue constructs., J. Biomech. Eng. 131 (2009) 111002. doi:10.1115/1.3128729.

[61] J. Malda, J. Visser, F.P. Melchels, T. Jüngst, W.E. Hennink, W.J.A. Dhert, et al., 25th Anniversary Article: Engineering Hydrogels for Biofabrication, Adv. Mater. 25 (2013) 5011-5028. doi:10.1002/adma.201302042.

[62] S. V Murphy, A. Skardal, A. Atala, Evaluation of hydrogels for bio-printing applications, J. Biomed. Mater. Res. Part A. 101A (2013) 272-284. doi:10.1002/jbm.a.34326. 
[63] R. Levato, J. Visser, J. Planell, E. Engel, J. Malda, M. Mateos-Timoneda, Biofabrication of tissue constructs by 3D bioprinting of cell-laden microcarriers, Biofabrication. 6 (2014) 35020. http://stacks.iop.org/1758-5090/6/i=3/a=035020.

[64] F. Pati, J. Jang, D.-H. Ha, S. Won Kim, J.-W. Rhie, J.-H. Shim, et al., Printing threedimensional tissue analogues with decellularized extracellular matrix bioink., Nat. Commun. 5 (2014) 3935. doi:10.1038/ncomms4935.

[65] M. Gou, X. Qu, W. Zhu, M. Xiang, J. Yang, K. Zhang, et al., Bio-inspired detoxification using 3D-printed hydrogel nanocomposites., Nat. Commun. 5 (2014) 3774. doi:10.1038/ncomms4774.

[66] B. Duan, L. Hockaday, K.H. Kang, J.T. Butcher, 3D Bioprinting of heterogeneous aortic valve conduits with alginate/gelatin hydrogels, J. Biomed. Mater. Res. - Part A. $101 \mathrm{~A}$ (2013) 1255-1264. doi:10.1002/jbm.a.34420.

[67] R. Chang, J. Nam, W. Sun, Effects of dispensing pressure and nozzle diameter on cell survival from solid freeform fabrication-based direct cell writing., Tissue Eng. Part A. 14 (2008) 41-48. doi:10.1089/ten.a.2007.0004.

[68] C.M. Owens, F. Marga, G. Forgacs, C.M. Heesch, Biofabrication and testing of a fully cellular nerve graft, Biofabrication. 5 (2013) 45007. http://dx.doi.org/10.1088/17585082/5/4/045007

[69] Yin Yu, I.T. Ozbolat, Tissue strands as "bioink" for scale-up organ printing., Conf. Proc. Annu. Int. Conf. IEEE. 2014 (2014) 1428-31. doi:10.1109/EMBC.2014.6943868.

[70] D.F. Duarte Campos, A. Blaeser, A. Korsten, S. Neuss, J. Jäkel, M. Vogt, et al., The Stiffness and Structure of Three-Dimensional Printed Hydrogels Direct the Differentiation of Mesenchymal Stromal Cells Toward Adipogenic and Osteogenic Lineages., Tissue Eng. Part A. 00 (2014) 1-17. doi:10.1089/ten.TEA.2014.0231.

[71] A. Gregor, J. Hošek, 3D printing methods of biological scaffolds used in tissue engineering, Rom. Rev. Precis. Mech. Opt. Mechatronics. 3 (2011) 143-148.

[72] C.M. Smith, A. Stone, R.L. Stewart, M.W. Simpkins, A.M. Kachurin, D. Ph, et al., ThreeDimensional BioAssembly Tool for Generating Viable Tissue-Engineered Constructs, 
Tissue Eng. 10 (2004) 1566-1576. doi:10.1089/ten.2004.10.1566.

[73] D.L. Cohen, J.I. Lipton, L.J. Bonassar, H. Lipson, Additive manufacturing for in situ repair of osteochondral defects., Biofabrication. 2 (2010) 035004. doi:10.1088/1758$5082 / 2 / 3 / 035004$.

[74] J.L. Drury, D.J. Mooney, Hydrogels for tissue engineering: Scaffold design variables and applications, Biomaterials. 24 (2003) 4337-4351. doi:10.1016/S0142-9612(03)00340-5.

[75] E.M. Ahmed, Hydrogel: Preparation, characterization, and applications, J. Adv. Res. 6 (2013) 105-121. doi:10.1016/j.jare.2013.07.006.

[76] J. Cohen, K.L. Zaleski, G. Nourissat, T.P. Julien, M. Randolph, M.J. Yaremchuk, Survival of porcine mesenchymal stem cells over the alginate recovered cellular method., J. Biomed. Mater. Res. A. 96 (2011) 93-9. doi:10.1002/jbm.a.32961.

[77] J. Jia, D.J. Richards, S. Pollard, Y. Tan, J. Rodriguez, R.P. Visconti, et al., Engineering alginate as bioink for bioprinting., Acta Biomater. 10 (2014) 4323-31. doi:10.1016/j.actbio.2014.06.034.

[78] S. Wüst, R. Müller, S. Hofmann, "3D bioprinting of complex channels - Effects of material, orientation, geometry and cell embedding," J. Biomed. Mater. Res. A. (2014). doi:10.1002/jbm.a.35393.

[79] S. Ahn, H. Lee, L.J. Bonassar, G. Kim, Cells (MC3T3-E1)-laden alginate scaffolds fabricated by a modified solid-freeform fabrication process supplemented with an aerosol spraying, Biomacromolecules. 13 (2012) 2997-3003. doi:10.1021/bm3011352.

[80] I.T. Ozbolat, H. Chen, Y. Yu, Development of "Multi-arm Bioprinter" for hybrid biofabrication of tissue engineering constructs, Robot. Comput. Integr. Manuf. 30 (2014) 295-304. doi:10.1016/j.rcim.2013.10.005.

[81] S. Ahn, H. Lee, J. Puetzer, L.J. Bonassar, G. Kim, Fabrication of cell-laden threedimensional alginate-scaffolds with an aerosol cross-linking process, J. Mater. Chem. 22 (2012) 18735. doi:10.1039/c2jm33749e.

[82] L. Geng, W. Feng, D.W. Hutmacher, Y.S. Wong, H.T. Loh, J.Y.H. Fuh, Direct writing of 
chitosan scaffolds using a robotic system, Rapid Prototyp. J. 11 (2005) 90-97. doi:10.1108/13552540510589458.

[83] X.R.X. Zhang Leilei, Huang Jiwei, Si Ting, Coaxial electrospray of microparticles and nanoparticles for biomedical applications, Changes. 29 (2012) 997-1003. DOI: 10.1586/erd.12.58.

[84] P. Davoodi, F. Feng, Q. Xu, W.-C. Yan, Y.W. Tong, M.P. Srinivasan, et al., Coaxial electrohydrodynamic atomization: Microparticles for drug delivery applications, J. Control. Release. (2014). doi:10.1016/j.jconrel.2014.12.004.

[85] Y. Zhang, Y. Yu, A. Akkouch, A. Dababneh, F. Dolati, I.T. Ozbolat, In vitro study of directly bioprinted perfusable vasculature conduits, Biomater. Sci. 3 (2015) 134-143. doi:10.1039/C4BM00234B.

[86] Y. Zhang, Y. Yu, I.T. Ozbolat, Direct Bioprinting of Vessel-Like Tubular Microfluidic Channels, J. Nanotechnol. Eng. Med. 4 (2013) 21001. doi:10.1115/1.4024398.

[87] M. Ma, A. Chiu, G. Sahay, J.C. Doloff, N. Dholakia, J. Cohen, et al., Core-shell Hydrogel Microcapsules for Improved Islets Encapsulation, 2 (2014) 1-12. doi:10.1002/adhm.201200341.

[88] J.A. Rowley, G. Madlambayan, D.J. Mooney, Alginate hydrogels as synthetic extracellular matrix materials, Biomaterials. 20 (1999) 45-53. doi:http://dx.doi.org/10.1016/S01429612(98)00107-0.

[89] M.A. Lawson, J.E. Barralet, I. Wang, R.M. Shelton, J.T. Triffitt, Adhesion and Growth of Bone Marrow Stromal Cells on modified alginate hydrogels, Tissue Eng. 10 (2004) 14801491. doi:10.1089/ten.2004.10.1480.

[90] S.Y. Ong, J. Wu, S.M. Moochhala, M.H. Tan, J. Lu, Development of a chitosan-based wound dressing with improved hemostatic and antimicrobial properties, Biomaterials. 29 (2008) 4323-4332. doi:10.1016/j.biomaterials.2008.07.034.

[91] Y. Zhang, J.R. Venugopal, A. El-Turki, S. Ramakrishna, B. Su, C.T. Lim, Electrospun biomimetic nanocomposite nanofibers of hydroxyapatite/chitosan for bone tissue engineering, Biomaterials. $29 \quad$ (2008) 4314-4322. doi:10.1016/j.biomaterials.2008.07.038. 
[92] L. Ma, C. Gao, Z. Mao, J. Zhou, J. Shen, X. Hu, et al., Collagen/chitosan porous scaffolds with improved biostability for skin tissue engineering, Biomaterials. 24 (2003) 48334841. doi:10.1016/S0142-9612(03)00374-0.

[93] Y. Hong, H. Song, Y. Gong, Z. Mao, C. Gao, J. Shen, Covalently crosslinked chitosan hydrogel: properties of in vitro degradation and chondrocyte encapsulation., Acta Biomater. 3 (2007) 23-31. doi:10.1016/j.actbio.2006.06.007.

[94] T. Hao, N. Wen, J.K. Cao, H.B. Wang, S.H. Lü, T. Liu, et al., The support of matrix accumulation and the promotion of sheep articular cartilage defects repair in vivo by chitosan hydrogels, Osteoarthr. Cartil. 18 (2010) 257-265. doi:10.1016/j.joca.2009.08.007.

[95] X. Ren, Y. Kim, J. Zhou, Design and Fabrication of Chitosan for Application of Artificial Photosynthesis, 3 (2013) 739-746.

[96] M. Rinaudo, Chitin and chitosan: Properties and applications, Prog. Polym. Sci. 31 (2006) 603-632. doi:10.1016/j.progpolymsci.2006.06.001.

[97] K. Ye, R. Felimban, K. Traianedes, S.E. Moulton, G.G. Wallace, J. Chung, et al., Chondrogenesis of infrapatellar fat pad derived adipose stem cells in 3D printed chitosan scaffold, PLoS One. 9 (2014). doi:10.1371/journal.pone.0099410.

[98] M.C. Gómez-Guillén, B. Giménez, M.E. López-Caballero, M.P. Montero, Functional and bioactive properties of collagen and gelatin from alternative sources: A review, Food Hydrocoll. 25 (2011) 1813-1827. doi:10.1016/j.foodhyd.2011.02.007.

[99] J. Kuijpers, P.B. Van Wachem, M.J. Van Luyn, J. Plantinga, G.H.M. Engbers, J. Krijgsveld, et al., In vivo compatibility and degradation of crosslinked gelatin gels incorporated in knitted Dacron, J. Biomed. Mater. Res. 51 (2000) 136-145. doi:10.1002/(SICI)10974636(200007)51:1<136::AID-JBM18>3.0.CO;2-W.

[100] Q. Xing, K. Yates, C. Vogt, Z. Qian, M.C. Frost, F. Zhao, Increasing mechanical strength of gelatin hydrogels by divalent metal ion removal., Sci. Rep. 4 (2014) 4706. doi:10.1038/srep04706. 
[101] X. Wang, Y. Yan, Y. Pan, Z. Xiong, Generation of three-dimensional hepatocyte/gelatin structures with rapid prototyping system, Tissue $\ldots .12$ (2006) 83-90. doi:10.1089/ten.2006.12.ft-16.

[102] I. Van Den Bulcke, B. Bogdanov, N. De Rooze, E.H. Schacht, M. Cornelissen, H. Berghmans, Structural and rheological properties of methacrylamide modified gelatin hydrogels., Biomacromolecules. 1 (2000) 31-38. doi:10.1021/bm990017d.

[103] W. Lee, V. Lee, S. Polio, P. Keegan, J.H. Lee, K. Fischer, et al., On-demand threedimensional freeform fabrication of multi-layered hydrogel scaffold with fluidic channels, Biotechnol. Bioeng. 105 (2010) 1178-1186. doi:10.1002/bit.22613.

[104] H. Oxlund, T.T. Andreassen, The roles of hyaluronic acid, collagen and elastin in the mechanical properties of connective tissues, J. Anat. 131 (1980) 611-620.

[105] A. Migliore, M. Granata, Intra-articular use of hyaluronic acid in the treatment of osteoarthritis, Clin. Interv. Aging. 3 (2008) 365-369.

[106] J.Y. Park, J.-C. Choi, J.-H. Shim, J.-S. Lee, H. Park, S.W. Kim, et al., A comparative study on collagen type I and hyaluronic acid dependent cell behavior for osteochondral tissue bioprinting., Biofabrication. 6 (2014) 035004. doi:10.1088/1758-5082/6/3/035004.

[107] O. Jeon, S.J. Song, K.-J. Lee, M.H. Park, S.-H. Lee, S.K. Hahn, et al., Mechanical properties and degradation behaviors of hyaluronic acid hydrogels cross-linked at various crosslinking densities, Carbohydr. Polym. 70 (2007) 251-257. doi:10.1016/j.carbpol.2007.04.002.

[108] S. Gerecht, J. Burdick, L.S. Ferreira, S. Townsend, R. Langer, G. Vunjak-Novakovic, Hyaluronic acid hydrogel for controlled self-renewal and differentiation of human embryonic stem cells., Proc. Natl. Acad. Sci. U. S. A. 104 (2007) 11298-303. doi:10.1073/pnas.0703723104.

[109] N. Dana, V. Parker, M. Meredith, G. Mark, S. Lori, Photocrosslinkable Hyaluronan as a Scaffold for Articular Cartilage Repair, 32 (2004) 391-397.

[110] A. Skardal, A. Atala, Biomaterials for Integration with 3-D Bioprinting., Ann. Biomed. Eng. (2014). doi:10.1007/s10439-014-1207-1. 
[111] D.L. Elbert, Liquid-liquid two phase systems for the production of porous hydrogels and hydrogel microspheres for biomedical applications: A tutorial review, Acta Biomater. 7 (2012) 31-56. doi:10.1016/j.actbio.2010.07.028.

[112] R. Mooney, S. Haeger, R. Lawal, M. Mason, N. Shrestha, A. Laperle, et al., Control of Neural Cell Composition in Poly(Ethylene Glycol) Hydrogel Culture with Soluble Factors, Tissue Eng. Part A. 17 (2011) 2805-2815. doi:10.1089/ten.tea.2010.0654.

[113] S. Giovagnoli, T. Tsai, P.P. DeLuca, Formulation and release behavior of doxycyclinealginate hydrogel microparticles embedded into pluronic F127 thermogels as a potential new vehicle for doxycycline intradermal sustained delivery., AAPS PharmSciTech. 11 (2010) 212-220. doi:10.1208/s12249-009-9361-8.

[114] S.N.S. Alconcel, A.S. Baas, H.D. Maynard, FDA-approved poly(ethylene glycol)-protein conjugate drugs, Polym. Chem. 2 (2011) 1442. doi:10.1039/c1py00034a.

[115] F.M. Veronese, G. Pasut, PEGylation, successful approach to drug delivery, Drug Discov. Today. 10 (2005) 1451-1458. doi:10.1016/S1359-6446(05)03575-0.

[116] L. Hockaday, K.H. Kang, N.W. Colangelo, P.Y.C. Cheung, B. Duan, E. Malone, et al., Rapid 3D printing of anatomically accurate and mechanically heterogeneous aortic valve hydrogel scaffolds, Biofabrication. 4 (2012) 035005. doi:10.1088/1758-5082/4/3/035005.

[117] M. Zhang, T. Desai, M. Ferrari, Proteins and cells on PEG immobilized silicon surfaces, Biomaterials. 19 (1998) 953-960. doi:10.1016/S0142-9612(98)00026-X.

[118] N.E. Fedorovich, J. Alblas, J.R. de Wijn, W.E. Hennink, A.J. Verbout, W.J. Dhert, Hydrogels as extracellular matrices for skeletal tissue engineering: state-of-the-art and novel application in organ printing., Tissue Eng. 13 (2007) 1905-25. doi:10.1089/ten.2006.0175.

[119] P. Serwer, J.L. Allen, S.J. Hayes, Agarose gel electrophoresis ofbacteriophages and related particles III . Dependence of gel sieving on the agarose preparation, Electrophoresis. 4 (1983) 232-236. doi:10.1002/elps.1150040309.

[120] R. Landers, U. Hübner, R. Schmelzeisen, R. Mülhaupt, Rapid prototyping of scaffolds derived from thermoreversible hydrogels and tailored for applications in tissue engineering, Biomaterials. 23 (2002) 4437-4447. doi:10.1016/S0142-9612(02)00139-4. 
[121] H.A. Awad, M.Q. Wickham, H. Leddy, J.M. Gimble, F. Guilak, Chondrogenic differentiation of adipose-derived adult stem cells in agarose, alginate, and gelatin scaffolds, Biomaterials. 25 (2004) 3211-3222. doi:10.1016/j.biomaterials.2003.10.045.

[122] D.F. Duarte Campos, A. Blaeser, M. Weber, J. Jäkel, S. Neuss, W. Jahnen-Dechent, et al., Three-dimensional printing of stem cell-laden hydrogels submerged in a hydrophobic high-density fluid., Biofabrication. 5 (2013) 015003. doi:10.1088/1758-5082/5/1/015003.

[123] D.M. Dean, A.P. Napolitano, J. Youssef, J.R. Morgan, Rods, tori, and honeycombs: the directed self-assembly of microtissues with prescribed microscale geometries., FASEB J. 21 (2007) 4005-4012. doi:10.1096/fj.07-8710com.

[124] V. Mironov, V. Kasyanov, R.R. Markwald, Organ printing: From bioprinter to organ biofabrication line, Curr. Opin. Biotechnol. 22 (2011) 667-673. doi:10.1016/j.copbio.2011.02.006.

[125] M. Achilli, D. Mantovani, Tailoring Mechanical Properties of Collagen-Based Scaffolds for Vascular Tissue Engineering: The Effects of $\mathrm{pH}$, Temperature and lonic Strength on Gelation, Polymers (Basel). 2 (2010) 664-680. doi:10.3390/polym2040664.

[126] P.G. Grzesik, Wojciech J, Robey, Bone Matrix RGD Glycoproteins: Immunolocalization Bone Cells In Vitro, J. Bone Miner. Res. 9 (1994) 487-496. DOI: $10.1002 / \mathrm{jbmr} .5650090408$.

[127] M. Rücker, M.W. Laschke, D. Junker, C. Carvalho, A. Schramm, R. Mülhaupt, et al., Angiogenic and inflammatory response to biodegradable scaffolds in dorsal skinfold chambers of mice, Biomaterials. 27 (2006) 5027-5038. doi:10.1016/j.biomaterials.2006.05.033.

[128] C. Helary, I. Bataille, A. Abed, C. Illoul, A. Anglo, L. Louedec, et al., Concentrated collagen hydrogels as dermal substitutes, Biomaterials. 31 (2010) 481-490. doi:10.1016/j.biomaterials.2009.09.073.

[129] A. Skardal, D. Mack, E. Kapetanovic, A. Atala, J. Jackson, J. Yoo, et al., Bioprinted Amniotic Fluid-Derived Stem Cells Accelerate Healing of Large Skin Wounds, Stem Cells Transl. Med. (2012) 792-802. doi: 10.5966/sctm.2012-0088. 
[130] C.C. Chang, E.D. Boland, S.K. Williams, J.B. Hoying, Direct-write bioprinting threedimensional biohybrid systems for future regenerative therapies., J. Biomed. Mater. Res. B. Appl. Biomater. 98 (2011) 160-70. doi:10.1002/jbm.b.31831.

[131] L. Xi, T. Wang, F. Zhao, Q. Zheng, X. Li, J. Luo, et al., Evaluation of an injectable thermosensitive hydrogel as drug delivery implant for ocular glaucoma surgery, PLoS One. 9 (2014) 571-582. doi:10.1371/journal.pone.0100632.

[132] W. Wu, A. DeConinck, J. Lewis, Omnidirectional printing of 3D microvascular networks., Adv. Mater. 23 (2011) H178-83. doi:10.1002/adma.201004625.

[133] C.M. Homenick, G. de Silveira, H. Sheardown, A. Adronov, Pluronics as crosslinking agents for collagen: novel amphiphilic hydrogels, Polym. Int. 60 (2011) 458-465. doi:10.1002/pi.2969.

[134] H.K. Kleinman, G.R. Martin, Matrigel: Basement membrane matrix with biological activity, Semin. Cancer Biol. 15 (2005) 378-386. doi:10.1016/j.semcancer.2005.05.004.

[135] Z. Li, J. Guan, Hydrogels for cardiac tissue engineering, Polymers. 3 (2011) 740-761. doi:10.3390/polym3020740.

[136] N.E. Fedorovich, J.R. De Wijn, A.J. Verbout, J. Alblas, W.J. Dhert, Three-dimensional fiber deposition of cell-laden, viable, patterned constructs for bone tissue printing., Tissue Eng. Part A. 14 (2008) 127-133. doi:10.1089/ten.a.2007.0158.

[137] N.E. Fedorovich, H.M. Wijnberg, W.J. Dhert, J. Alblas, Distinct tissue formation by heterogeneous printing of osteo- and endothelial progenitor cells., Tissue Eng. Part A. 17 (2011) 2113-2121. doi:10.1089/ten.tea.2011.0019.

[138] J.R. Lott, J.W. McAllister, S. Arvidson, F.S. Bates, T.P. Lodge, Fibrillar structure of methylcellulose hydrogels, Biomacromolecules. 14 (2013) 2484-2488. doi:10.1021/bm400694r.

[139] K. Kobayashi, C. Huang, T.P. Lodge, Thermoreversible Gelation of Aqueous Methylcellulose Solutions, Macromolecules. 32 (1999) 7070-7077. doi:10.1021/ma990242n. 
[140] S. Thirumala, J. Gimble, R. Devireddy, Methylcellulose Based Thermally Reversible Hydrogel System for Tissue Engineering Applications, Cells. 2 (2013) 460-475. doi:10.3390/cells2030460.

[141] C. Trojani, P. Weiss, J.F. Michiels, C. Vinatier, J. Guicheux, G. Daculsi, et al., Threedimensional culture and differentiation of human osteogenic cells in an injectable hydroxypropylmethylcellulose hydrogel, Biomaterials. 26 (2005) 5509-5517. doi:10.1016/j.biomaterials.2005.02.001.

[142] C. Vinatier, D. Magne, P. Weiss, C. Trojani, N. Rochet, G.F. Carle, et al., A silanized hydroxypropyl methylcellulose hydrogel for the three-dimensional culture of chondrocytes, $\quad$ Biomaterials. $\quad 26 \quad$ (2005) 6643-6651. doi:10.1016/j.biomaterials.2005.04.057.

[143] C. Wu, Y. Luo, G. Cuniberti, Y. Xiao, M. Gelinsky, Three-dimensional printing of hierarchical and tough mesoporous bioactive glass scaffolds with a controllable pore architecture, excellent mechanical strength and mineralization ability, Acta Biomater. 7 (2011) 2644-2650. doi:10.1016/j.actbio.2011.03.009.

[144] K. Markstedt, A. Mantas, I. Tournier, H. Martínez Ávila, D. Hägg, P. Gatenholm, 3D Bioprinting Human Chondrocytes with Nanocellulose-Alginate Bioink for Cartilage Tissue Engineering Applications, Biomacromolecules. (2015) 150325142328001. doi:10.1021/acs.biomac.5b00188.

[145] H. Li, Y. Dai, J. Shu, R. Yu, Y. Guo, J. Chen, Spheroid cultures promote the stemness of corneal stromal cells, Tissue Cell. 47 (2015) 39-48. doi:10.1016/j.tice.2014.10.008.

[146] Y. Yu, M.J. Brouillette, D. Seol, H. Zheng, J.A. Buckwalter, J.A. Martin, Functional FullThickness Articular Cartilage Repair by rhSDF-1 $\alpha$ Loaded Fibrin/HA Hydrogel Network via Chondrogenic Progenitor Cells Homing, Arthritis Rheum. (2012) 1-30. doi:10.1002/art.

[147] Y.-B. Lee, S. Polio, W. Lee, G. Dai, L. Menon, R.S. Carroll, et al., Bio-printing of collagen and VEGF-releasing fibrin gel scaffolds for neural stem cell culture., Exp. Neurol. 223 (2010) 645-52. doi:10.1016/j.expneurol.2010.02.014.

[148] T. Xu, C. Gregory, P. Molnar, X. Cui, S. Jalota, S.B. Bhaduri, et al., Viability and electrophysiology of neural cell structures generated by the inkjet printing method, 
Biomaterials. 27 (2006) 3580-3588. doi:10.1016/j.biomaterials.2006.01.048.

[149] X. Cui, T. Boland, Human microvasculature fabrication using thermal inkjet printing technology, Biomaterials. 30 (2009) 6221-7. doi:10.1016/j.biomaterials.2009.07.056.

[150] Wei Xu, Xiaohong Wang, Yongnian Yan, Wei Zheng, Zhuo Xiong, Feng Lin, et al., Rapid Prototyping Three-Dimensional Cell/Gelatin/Fibrinogen Constructs for Medical Regeneration, J. Bioact. Compat. Polym. 22 (2007) 363-377. doi:10.1177/0883911507079451.

[151] C. Li, A. Faulkner-Jones, A.R. Dun, J. Jin, P. Chen, Y. Xing, et al., Rapid Formation of a Supramolecular Polypeptide-DNA Hydrogel for In Situ Three-Dimensional Multilayer Bioprinting., Angew. Chem. Int. Ed. Engl. (2015) 1-6. doi:10.1002/anie.201411383.

[152] I.T. Ozbolat, B. Koc, Modeling of Spatially Controlled Biomolecules in Three-Dimensional Porous Alginate Structures, J. Med. Device. 4 (2010) 041003. doi:10.1115/1.4002612.

[153] I.T. Ozbolat, B. Koc, Multi-function based modeling of 3D heterogeneous wound scaffolds for improved wound healing, Comput. Aided. Des. Appl. 8 (2011) 43-57. doi:10.3722/cadaps.2011.43-57.

[154] L. Mogas-Soldevila, J. Duro-Royo, N. Oxman, Water-Based Robotic Fabrication: LargeScale Additive Manufacturing of Functionally Graded Hydrogel Composites via Multichamber Extrusion, 3D Print. Addit. Manuf. 1 (2014) 141-151. doi:10.1089/3dp.2014.0014.

[155] I. Ozbolat, Scaffold-based or Scaffold-free Bioprinting: Competing or Complementing Approaches?, J. Nanotechnol. Eng. Med. 6 (2015) 024701. doi:10.1115/1.4030414.

[156] J. Yu, K.L. Christman, E. Chin, R.E. Sievers, M. Saeed, R.J. Lee, Restoration of left ventricular geometry and improvement of left ventricular function in a rodent model of chronic ischemic cardiomyopathy., J. Thorac. Cardiovasc. Surg. 137 (2009) 180-7. doi:10.1016/j.jtcvs.2008.08.036.

[157] M. Gruene, M. Pflaum, C. Hess, S. Diamantouros, S. Schlie, A. Deiwick, et al., Laser Printing of Three-Dimensional Multicellular Arrays for Studies of Cell-Cell and CellEnvironment Interactions, Tissue Eng. Part C Methods. 17 (2011) 973-982. doi:10.1089/ten.tec.2011.0185. 
[158] J. Malda, C. van Blitterswijk, M. Grojec, D.E. Martens, J. Tramper, J. Riesle, Expansion of bovine chondrocytes on microcarriers enhances redifferentiation., Tissue Eng. 9 (2003) 939-948. doi:10.1089/107632703322495583.

[159] A. Skardal, S.F. Sarker, A. Crabbé, C. Nickerson, G.D. Prestwich, The generation of 3-D tissue models based on hyaluronan hydrogel-coated microcarriers within a rotating wall vessel bioreactor, Biomaterials. $31 \quad$ (2010) 8426-8435. doi:10.1016/j.biomaterials.2010.07.047.

[160] S.J. Curran, R. Chen, J.M. Curran, J. Hunt, Expansion of human chondrocytes in an intermittent stirred flow bioreactor, using modified biodegradable microspheres., Tissue Eng. 11 (2005) 1312-1322. doi:10.1089/ten.2005.11.1312.

[161] Y. Bayram, M. Deveci, N. Imirzalioglu, Y. Soysal, M. Sengezer, The cell based dressing with living allogenic keratinocytes in the treatment of foot ulcers: A case study, Br. J. Plast. Surg. 58 (2005) 988-996. doi:10.1016/j.bjps.2005.04.031.

[162] J.Y. Liu, J. Hafner, G. Dragieva, B. Seifert, G. Burg, Autologous cultured keratinocytes on porcine gelatin microbeads effectively heal chronic venous leg ulcers, Wound Repair Regen. 12 (2004) 148-156. doi:10.1111/j.1067-1927.2004.012205.x.

[163] A.H. Shikani, D.J. Fink, A. Sohrabi, P. Phan, A. Polotsky, D.S. Hungerford, et al., Propagation of human nasal chondrocytes in microcarrier spinner culture, Am. J. Rhinol. 18 (2004) 105-112.

[164] M. Overstreet, A. Sohrabi, A. Polotsky, D.S. Hungerford, C.G. Frondoza, Collagen microcarrier spinner culture promotes osteoblast proliferation and synthesis of matrix proteins., In Vitro Cell. Dev. Biol. Anim. 39 (2003) 228-234. doi:10.1290/1543706X(2003)039.

[165] M. Yamamoto, D. James, H. Li, J. Butler, S. Rafii, S. Rabbany, Generation of stable cocultures of vascular cells in a honeycomb alginate scaffold., Tissue Eng. Part A. 16 (2010) 299-308. doi:10.1089/ten.tea.2009.0010.

[166] B. Liau, N. Christoforou, K.W. Leong, N. Bursac, Pluripotent stem cell-derived cardiac tissue patch with advanced structure and function, Biomaterials. 32 (2011) 9180-9187. doi:10.1016/j.biomaterials.2011.08.050. 
[167] D. Zhang, I.Y. Shadrin, J. Lam, H.Q. Xian, H.R. Snodgrass, N. Bursac, Tissue-engineered cardiac patch for advanced functional maturation of human ESC-derived cardiomyocytes, Biomaterials. 34 (2013) 5813-5820. doi:10.1016/j.biomaterials.2013.04.026.

[168] S. Breslin, L. O'Driscoll, Three-dimensional cell culture: the missing link in drug discovery, Drug Discov. Today. 18 (2013) 240-249. doi:http://dx.doi.org/10.1016/j.drudis.2012.10.003.

[169] Y. Torisawa, B. Mosadegh, G.D. Luker, M. Morell, K.S. O’Shea, S. Takayama, Microfluidic hydrodynamic cellular patterning for systematic formation of co-culture spheroids., Integr. Biol. (Camb). 1 (2009) 649-654. doi:10.1039/b915965g.

[170] A.Y. Hsiao, Y.S. Torisawa, Y.C. Tung, S. Sud, R.S. Taichman, K.J. Pienta, et al., Microfluidic system for formation of PC-3 prostate cancer co-culture spheroids, Biomaterials. 30 (2009) 3020-3027. doi:10.1016/j.biomaterials.2009.02.047.

[171] A. Khademhosseini, L. Ferreira, J. Blumling, J. Yeh, J.M. Karp, J. Fukuda, et al., Co-culture of human embryonic stem cells with murine embryonic fibroblasts on microwellpatterned substrates, Biomaterials. $27 \quad$ (2006) 5968-5977. doi:10.1016/j.biomaterials.2006.06.035.

[172] Y. Tan, D.J. Richards, T.C. Trusk, R.P. Visconti, M.J. Yost, M.S. Kindy, et al., 3D printing facilitated scaffold-free tissue unit fabrication, Biofabrication. 6 (2014) 024111. doi:10.1088/1758-5082/6/2/024111.

[173] A. Akkouch, Y. Yu, I.T. Ozbolat, Microfabrication of scaffold-free tissue strands for threedimensional tissue engineering, Biofabrication. 7 (2015) 31002. doi:10.1088/17585090/7/3/031002.

[174] I.T. Ozbolat, Y. Yu, Bioprinting Toward Organ Fabrication: Challenges and Future Trends, 60 (2013) 691-699. doi: 10.1109/TBME.2013.2243912.

[175] T. Achilli, J. Meyer, J.R. Morgan, Advances in the formation, use and understanding of multi- cellular spheroids, Expert Opin. Biol. Ther. 12 (2012) 1347-1360. doi:10.1517/14712598.2012.707181.Advances. 
[176] T. Katakai, T. Hara, J.H. Lee, H. Gonda, M. Sugai, A. Shimizu, A novel reticular stromal structure in lymph node cortex: An immuno-platform for interactions among dendritic cells, $T$ cells and $B$ cells, Int. Immunol. 16 (2004) 1133-1142. doi:10.1093/intimm/dxh113.

[177] C. Kucukgul, S.B. Ozler, I. Inci, E. Karakas, S. Irmak, D. Gozuacik, et al., 3D Bioprinting of Biomimetic Aortic Vascular Constructs with Self-Supporting Cells, Biotechnol. Bioeng. 112 (2014). doi:10.1002/bit.25493.

[178] H. Ott, T. Matthiesen, S.-K. Goh, L. Black, S. Kren, T. Netoff, et al., Perfusiondecellularized matrix: using nature's platform to engineer a bioartificial heart, Nat. Med. 14 (2008) 213-221. doi:10.1038/nm1684.

[179] T.-Y. Lu, B. Lin, J. Kim, M. Sullivan, K. Tobita, G. Salama, et al., Repopulation of decellularized mouse heart with human induced pluripotent stem cell-derived cardiovascular progenitor cells, Nat Commun. 4 (2013). doi:10.1038/ncomms3307.

[180] J.J. Song, J.P. Guyette, S.E. Gilpin, G. Gonzalez, J.P. Vacanti, H.C. Ott, Regeneration and experimental orthotopic transplantation of a bioengineered kidney., Nat. Med. 19 (2013) 646-51. doi:10.1038/nm.3154.

[181] B.E. Uygun, A. Soto-Gutierrez, H. Yagi, M.-L. Izamis, M. Guzzardi, C. Shulman, et al., Organ reengineering through development of a transplantable recellularized liver graft using decellularized liver matrix., Nat. Med. 16 (2010) 814-820. doi:10.1038/nm.2170.

[182] K.E.M. Benders, P.R. Van Weeren, S.F. Badylak, D.B.F. Saris, W.J. Dhert, J. Malda, Extracellular matrix scaffolds for cartilage and bone regeneration, Trends Biotechnol. 31 (2013) 169-176. doi:10.1016/j.tibtech.2012.12.004.

[183] C. Conrad, C. Schuetz, B. Clippinger, J.P. Vacanti, J.F. Markmann, H.C. Ott, Bio-engineered endocrine pancreas based on decellularized pancreatic matrix and mesenchymal stem cell/islet cell coculture, J. Am. Coll. Surg. 211 (2010) S62. doi:10.1016/j.jamcollsurg.2010.06.161.

[184] J.J. Song, H.C. Ott, Organ engineering based on decellularized matrix scaffolds, Trends Mol. Med. 17 (2011) 424-432. doi:http://dx.doi.org/10.1016/j.molmed.2011.03.005.

[185] S. Coatnye, B. Gandhi, B. Park, D. Dzilno, E. Tapia, G. Kamarthy, et al., 3D Bio-Printing, 
Tech. Rep. No. 2013.04.17. (2013).

[186] J.-H. Shim, J.-S. Lee, J.Y. Kim, D.-W. Cho, Bioprinting of a mechanically enhanced threedimensional dual cell-laden construct for osteochondral tissue engineering using a multihead tissue/organ building system, J. Micromechanics Microengineering. 22 (2012) 085014. doi:10.1088/0960-1317/22/8/085014.

[187] E. Malone, H. Lipson, Fab@Home: the personal desktop fabricator kit, Rapid Prototyp. J. 13 (2007) 245-255. doi:10.1108/13552540710776197.

[188] Root Analysis Business Research \& Consulting, 3D bioprinting market, 2014-2030 (2014).

[189] V.K. Lee, D.Y. Kim, H. Ngo, Y. Lee, L. Seo, S.-S. Yoo, et al., Creating perfused functional vascular channels using 3D bio-printing technology, Biomaterials. 35 (2014) 8092-8102. doi:http://dx.doi.org/10.1016/j.biomaterials.2014.05.083.

[190] Q. Gao, Y. He, J. Fu, A. Liu, L. Ma, Coaxial nozzle-assisted 3D bioprinting with built-in microchannels for nutrients delivery, Biomaterials. 61 (2015) 203-215. doi:10.1016/j.biomaterials.2015.05.031.

[191] Y. Zhang, Y. Yu, H. Chen, I.T. Ozbolat, Characterization of Printable Cellular Micro-fluidic Channels for Tissue Engineering, Biofabrication. 5 (2013) 24004. http://dx.doi.org/10.1088/1758-5082/5/2/025004.

[192] F. Dolati, Y. Yu, Y. Zhang, A. Jesus, E.A. Sander, I.T. Ozbolat, In vitro evaluation of carbonnanotube-reinforced bioprintable vascular conduits, Nanotechnology. 25 (2014) 145101. http://stacks.iop.org/0957-4484/25/i=14/a=145101.

[193] L.E. Bertassoni, M. Cecconi, V. Manoharan, M. Nikkhah, J. Hjortnaes, A.L. Cristino, et al., Hydrogel bioprinted microchannel networks for vascularization of tissue engineering constructs., Lab Chip. 14 (2014) 2202-11. doi:10.1039/c4lc00030g.

[194] L. Zhao, V.K. Lee, S.-S. Yoo, G. Dai, X. Intes, The integration of 3-D cell printing and mesoscopic fluorescence molecular tomography of vascular constructs within thick hydrogel scaffolds., Biomaterials. $33 \quad$ (2012) 5325-32. doi:10.1016/j.biomaterials.2012.04.004. 
[195] M.S. Ozturk, V.K. Lee, L. Zhao, G. Dai, X. Intes, Mesoscopic fluorescence molecular tomography of reporter genes in bioprinted thick tissue., J. Biomed. Opt. 18 (2013) 100501. doi:10.1117/1.JBO.18.10.100501.

[196] J.S. Miller, K.R. Stevens, M.T. Yang, B.M. Baker, D.-H.T. Nguyen, D.M. Cohen, et al., Rapid casting of patterned vascular networks for perfusable engineered three-dimensional tissues, Nat Mater. 11 (2012) 768-774. http://dx.doi.org/10.1038/nmat3357.

[197] V. Lee, A. Lanzi, H. Ngo, S.-S. Yoo, P. Vincent, G. Dai, Generation of Multi-scale Vascular Network System Within 3D Hydrogel Using 3D Bio-printing Technology, Cell. Mol. Bioeng. (2014) 1-13. doi:10.1007/s12195-014-0340-0.

[198] S. Chung, R. Sudo, P.J. Mack, C.-R. Wan, V. Vickerman, R.D. Kamm, Cell migration into scaffolds under co-culture conditions in a microfluidic platform., Lab Chip. 9 (2009) 269275. doi:10.1039/b807585a.

[199] W. Sheng, O.O. Ogunwobi, T. Chen, J. Zhang, T.J. George, C. Liu, et al., Capture, release and culture of circulating tumor cells from pancreatic cancer patients using an enhanced mixing chip., Lab Chip. 14 (2014) 89-98. doi:10.1039/c3lc51017d.

[200] W.-Y. Yeong, C.-K. Chua, K.-F. Leong, M. Chandrasekaran, Rapid prototyping in tissue engineering: challenges and potential., Trends Biotechnol. 22 (2004) 643-52. doi:10.1016/j.tibtech.2004.10.004.

[201] Y. Yu, Y. Zhang, J. Martin, I.T. Ozbolat, Evaluation of cell viability and functionality in vessel-like bioprintable cell-laden tubular channels., J. Biomech. Eng. 135 (2013) 91011. doi:10.1115/1.4024575.

[202] Nordson EFD, Http://www.nordson.com (2015).

[203] D.A. Bruzewicz, M. Reches, G.M. Whitesides, Low-Cost Printing of Poly(dimethylsiloxane) Barriers to Define Microchannels in Paper, Analytical Chemisty. 80 (2008) 3387-3392. DOI: 10.1021/ac702605a.

[204] S.B. Bammesberger, S. Kartmann, L. Tanguy, D. Liang, K. Mutschler, A. Ernst, et al., A lowcost, normally closed, solenoid valve for non-contact dispensing in the sub- $\mu$ l range, Micromachines. 4 (2013) 9-21. doi:10.3390/mi4010009. 
[205] I.T. Ozbolat, Bioprinting scale-up tissue and organ constructs for transplantation, Trends Biotechnol. (2015) 1-6. doi:10.1016/j.tibtech.2015.04.005.

[206] L. Koch, S. Kuhn, H. Sorg, M. Gruene, S. Schlie, R. Gaebel, et al., Laser printing of skin cells and human stem cells., Tissue Eng. Part C. Methods. 16 (2010) 847-854. doi:10.1089/ten.tec.2009.0397.

[207] Z. Wang, W. Wu, Q. Yang, Y. Li, C.H. Noh, In-situ fabrication of flexible vertically integrated electronic circuits by inkjet printing, J. Alloys Compd. 486 (2009) 706-710. doi:10.1016/j.jallcom.2009.07.044.

[208] I. Hussain, S.Z. Hussain, Habib-ur-Rehman, A. Ihsan, A. Rehman, Z.M. Khalid, et al., In situ growth of gold nanoparticles on latent fingerprints-from forensic applications to inkjet printed nanoparticle patterns., Nanoscale. 2 (2010) 2575-2578. doi:10.1039/c0nr00593b.

[209] A.J. Lopes, I.H. Lee, E. Macdonald, R. Quintana, R. Wicker, Laser curing of silver-based conductive inks for in situ 3D structural electronics fabrication in stereolithography, J. Mater. Process. Technol. 214 (2014) 1935-1945. doi:10.1016/j.jmatprotec.2014.04.009.

[210] T. Xu, K.W. Binder, M.Z. Albanna, D. Dice, W. Zhao, J.J. Yoo, et al., Hybrid printing of mechanically and biologically improved constructs for cartilage tissue engineering applications., Biofabrication. 5 (2013) 015001. doi:10.1088/1758-5082/5/1/015001.

[211] E.D.F. Ker, B. Chu, J. Phillippi, B. Gharaibeh, J. Huard, L.E. Weiss, et al., Engineering spatial control of multiple differentiation fates within a stem cell population, Biomaterials. 32 (2011) 3413-3422. doi:10.1016/j.biomaterials.2011.01.036.

[212] J.K. Carrow, A.K. Gaharwar, Bioinspired Polymeric Nanocomposites for Regenerative Medicine, Macromol. Chem. Phys. (2014) n/a-n/a. doi:10.1002/macp.201400427.

[213] M.A. Kay, State-of-the-art gene-based therapies: the road ahead, Nat Rev Genet. 12 (2011) 316-328. http://dx.doi.org/10.1038/nrg2971.

[214] C.H. Evans, S.C. Ghivizzani, P.D. Robbins, Progress and Prospects: genetic treatments for disorders of bones and joints, Gene Ther. 16 (2009) 944-952. http://dx.doi.org/10.1038/gt.2009.73. 
[215] S. Elangovan, S.R. D'Mello, L. Hong, R.D. Ross, C. Allamargot, D. V Dawson, et al., The enhancement of bone regeneration by gene activated matrix encoding for platelet derived growth factor, Biomaterials. $35 \quad$ (2014) 737-747. doi:http://dx.doi.org/10.1016/j.biomaterials.2013.10.021.

[216] T. Aper, O.E. Teebken, G. Steinhoff, A. Haverich, Use of a fibrin preparation in the engineering of a vascular graft model., Eur. J. Vasc. Endovasc. Surg. 28 (2004) 296-302. doi:10.1016/j.ejvs.2004.05.016.

[217] J.W. Nichol, S.T. Koshy, H. Bae, C.M. Hwang, S. Yamanlar, A. Khademhosseini, Cell-laden microengineered gelatin methacrylate hydrogels, Biomaterials. 31 (2010) 5536-5544. doi:10.1016/j.biomaterials.2010.03.064.

[218] S.E. Franco J., Hunger P., Launey M.E., Tomsia A.P., Direct-Write Assembly of Calcium Phosphate Scaffolds Using a Water-Based Hydrogel, Acta Biomater. 6 (2011) 218-228. doi:10.1016/j.actbio.2009.06.031.

[219] J.R. Gallant, L.L. Traeger, J.D. Volkening, H. Moffett, et al., Genomic basis for the convergent evolution of electric organs, Science. 344 (2014) 1522-1525.DOI: 10.1126/science.1254432.

[220] B. Fritzsch, Electric organs: History and potential, Science. 345 (2014) 631-632. doi: 10.1126/science.345.6197.631-b

[221] K.B. Hellman, Tissue Engineering: Translating Science to Product. in Topics in Tissue Eng. (2008) 1-28.

[222] N.E. Fedorovich, W. Schuurman, H.M. Wijnberg, H.-J. Prins, P.R. van Weeren, J. Malda, et al., Biofabrication of osteochondral tissue equivalents by printing topologically defined, cell-laden hydrogel scaffolds., Tissue Eng. Part C. Methods. 18 (2012) 33-44. doi:10.1089/ten.TEC.2011.0060.

[223] J.-S. Lee, J.M. Hong, J.W. Jung, J.-H. Shim, J.-H. Oh, D.-W. Cho, 3D printing of composite tissue with complex shape applied to ear regeneration, Biofabrication. 6 (2014) 024103. doi:10.1088/1758-5082/6/2/024103.

[224] V. Lee, G. Singh, J.P. Trasatti, C. Bjornsson, X. Xu, T.N. Tran, et al., Design and fabrication of human skin by three-dimensional bioprinting, Tissue Eng. Part C. Methods. 20 (2014) 
473-84. doi:10.1089/ten.TEC.2013.0335.

[225] W. Lee, J. Pinckney, V. Lee, J.-H. Lee, K. Fischer, S. Polio, et al., Three-dimensional bioprinting of rat embryonic neural cells, Neuroreport. 20 (2009) 798-803. doi:10.1097/WNR.0b013e32832b8be4.

[226] A. Tocchio, M. Tamplenizza, F. Martello, I. Gerges, E. Rossi, S. Argentiere, et al., Versatile fabrication of vascularizable scaffolds for large tissue engineering in bioreactor, Biomaterials. 45 (2015) 124-31. doi:10.1016/j.biomaterials.2014.12.031.

[227] S.F. Khattak, S.R. Bhatia, S.C. Roberts, Pluronic F127 as a cell encapsulation material: utilization of membrane-stabilizing agents, Tissue Eng. 11 (2005) 974-83. doi:10.1089/ten.2005.11.974.

[228] A. Skardal, J. Zhang, L. McCoard, S. Oottamasathien, G.D. Prestwich, Dynamically crosslinked gold nanoparticle - hyaluronan hydrogels, Adv. Mater. 22 (2010) 4736-40. doi:10.1002/adma.201001436.

[229] F. Pati, J.H. Shim, J.S. Lee, D.W. Cho, 3D printing of cell-laden constructs for heterogeneous tissue regeneration, Manuf. Lett. 1 (2013) 49-53. doi:10.1016/j.mfglet.2013.09.004.

[230] S.J. Song, J. Choi, Y.D. Park, J.J. Lee, S.Y. Hong, K. Sun, A three-dimensional bioprinting system for use with a hydrogel-based biomaterial and printing parameter characterization, Artif. Organs. 34 (2010) 1044-1048. doi:10.1111/j.15251594.2010.01143.x.

[231] S.J. Song, J. Choi, Y.D. Park, S. Hong, J.J. Lee, C.B. Ahn, et al., Sodium Alginate HydrogelBased Bioprinting Using a Novel Multinozzle Bioprinting System, Artif. Organs. 35 (2011) 1132-1136. doi:10.1111/j.1525-1594.2011.01377.x.

[232] S. Hong, S.J. Song, J.Y. Lee, H. Jang, J. Choi, K. Sun, et al., Cellular behavior in micropatterned hydrogels by bioprinting system depended on the cell types and cellular interaction, J. Biosci. Bioeng. 116 (2013) 224-230. doi:10.1016/j.jbiosc.2013.02.011.

[233] G.Y. Huang, L.H. Zhou, Q.C. Zhang, Y.M. Chen, W. Sun, F. Xu, et al., Microfluidic hydrogels for tissue engineering., Biofabrication. 3 (2011) 012001. doi:10.1088/1758$5082 / 3 / 1 / 012001$. 
[234] H. Kang, I. Ko, C. Kim, S. Lee, A. Atala, J. Yoo, Biofabrication of Innervated Muscle Tissue for Accelerated Restoration of Muscle Function, Society of Biomaterials 29 (2013) 27157.

[235] G. Edwin, B. Emilie, H. Edward, S. Koen, P. Sharon, H. Deborah, et al., Three-dimensional (3D) bone tissues derived from stem cells as a novel model for mineralization, (2014) Stem Cell Meeting on the Mesa, La Jolla, CA.

[236] J.B. Robbins, C.M.O. Neill, V. Gorgen, S.C. Presnell, B.R. Shepherd, N. Ridge, et al., Bioprinted three-dimensional (3D) human liver constructs provide a model for interrogating liver biology, Mol. Biol. Cell (2013) 963. New Orleans, LA.

[237] J.B. Robbins, G. Vivian, M. Peter, B. Shephard, S. Presnell, A novel in vitro 3D bioprinted liver tissue system for drug development, (2013) the American Society of Experimental Biology, Boston, MA.

[238] S.M. King, V. Gorgen, S.C. Presnell, D.G. Nguyen, B.R. Shepherd, N. Ridge, et al., Development of 3D bioprinted human breast cancer for in vitro screening of therapeutics targeted against cancer progression, (2013) American Soceity of Biology, New Orleans, LA.

[239] K.B. Chien, E. Makridakis, R.N. Shah, Three Dimensional Printing of Soy Protein Scaffolds for Tissue Regeneration, Tissue Eng. Part C Methods. 19 (2012) 121026142624002. doi:10.1089/ten.TEC.2012.0383.

[240] N.T. Ersumo, K.L. Spiller, A.B. Selection, Effects of hydrogel properties and extrusion parameters on 3D bioprinting, Biomedical Engineering Conference. (2015) 25-26. 10.1109/NEBEC.2015.7117090.

[241] M.S. Mannoor, Z. Jiang, T. James, Y.L. Kong, K. a. Malatesta, W.O. Soboyejo, et al., 3D printed bionic ears, Nano Lett. 13 (2013) 2634-2639. doi:10.1021/nl4007744.

[242] H. Seyednejad, D. Gawlitta, W.J. a Dhert, C.F. Van Nostrum, T. Vermonden, W.E. Hennink, Preparation and characterization of a three-dimensional printed scaffold based on a functionalized polyester for bone tissue engineering applications, Acta Biomater. 7 (2011) 1999-2006. doi:10.1016/j.actbio.2011.01.018. 


\section{Table Captions}

Table 1: Hydrogels used in EBB

Table 2: Extrusion-based bioprinters and their applications 


\section{Figure Captions}

Figure 1: EBB systems: $(A)$ pneumatic micro-extrusion including $(A 1)$ valve-free and $(A 2)$ valvebased, (B) mechanical micro-extrusion including (B1) piston- or (B2) screw-driven and (C) solenoid micro-extrusion.

Figure 2: Bioink types used in EBB: (A) cells loaded in hydrogels, (B) polymer micro-carriers preloaded with cells [63], (C) tissue spheroids made of cells and ECM [21], (D) cell pellet in nozzle tip [41], (E) tissue strands [29] and (F) dECM before loading cells [51].

Figure 3: Processes configurations for various bioink materials: $(A)$ bioprinting cells in hydrogelbased bioink, (B1) bioplotting hydrogel bioink into a crosslinker reservoir, (B2) crosslinker deposition or spraying system, (B3) coaxial-nozzle system, (B4) bioprinting pre-crosslinked bioink, (B5) aerosol crosslinking system, (C) UV-integrated system, (D1) a heating-unit assisted barrel with cooling-unit assisted bioprinting stage, (D2) a cooling-unit assisted barrel with a heating-unit assisted nozzle tip, (E) multi-chamber single nozzle system, (F) bioprinting microcarriers (pre-loaded with cells) that can be extruded in hydrogels as a delivery medium, (G1) extrusion of tissue spheroids in a fugitive cell-inert hydrogel into a support mold for fusion and maturation of spheroids, (G2) bioprinting pre-aggregated cell pellet into a support material that is inert to cell adhesion, (G3) bioprinting tissue strands directly without using delivery medium or support mold, and $(\mathrm{H})$ bioprinting $\mathrm{dECM}$ within printed $\mathrm{PCL}$ frame to mechanically support gelation of dECM.

Figure 4: Bioprinting of vascular and vascularized tissue constructs: (A1) photograph of bioprinted agarose hydrogel filaments representing branched vascular network in a GelMA 
hydrogel block and (A2) a high resolution cross-sectional view of GelMA block stained for live and dead cells (reproduced/adapted with permission from Ref. [25]); (B1) sprouting of endothelium (stained with red fluorescent protein) into capillary network (stained with green fluorescent protein) within fibrin gel on day 9 and (B2) a high resolution image of the capillary network on day 14 (reproduced/adapted with permission from Ref. [197]); (C) an image acquired during evacuation of the fugitive ink showing channels in GelMA scaffold (upper-left) which were later glued with 10T1/2 fibroblasts, HUVECs and human dermal fibroblasts (HUDFs) (reproduced/adapted with permission from Ref. [27]); (D1) a scanning electron microscopy image of directly bioprinted vascular channels embedded in a large alginate construct (D2) showing L929 mouse fibroblasts in green (reproduced/adapted with permission from Ref. [190]); (E1) scaffold-free bioprinting of a branched vascular network using $300 \mu \mathrm{m}$ human skin fibroblast (HSF) spheroids (solid and broken arrows show 1.2 and $0.9 \mathrm{~mm}$ in vascular diameter, respectively), where spheroids (E2) fuse and maturate into tissue after 6 days of deposition (reproduced/adapted with permission from Ref. [21]); (F) fabrication of a perfusable tissue via integration of bioprinted vasculature and fibroblast tissue strands (reproduced/adapted with permission from Ref.[29]). Branched structure built of $300 \mu \mathrm{m}$ HSF spheroids with branches of $1.2 \mathrm{~mm}$ (solid arrow) and $0.9 \mathrm{~mm}$ (broken arrows). (D) The fused branched construct after 6 days of deposition.

Figure 5: In situ EBB: (A) bioprinting into a defect ex vivo, (B) bioprinting into defects on animals in vivo, and (C) futuristic bioprinting technologies for plastic surgery in operating rooms (image courtesy of Christopher Barnatt, ExplainingTheFuture.com). 
Figure 6: 3D printed cyborg ears: (A) bioprinting of anatomically correct cartilage scaffold loaded with chondrocytes along with printing of coil antenna; (B) scaffolds were cultured 10 weeks, resulting in neocartilaginous tissue in alginate matrix, (C) 3D printed complementary ears (right and left) demonstrated the ability to listen to stereophonic audio music (reproduced/adapted with permission from Ref. [83]). 
Table 1

\begin{tabular}{|c|c|c|c|c|c|c|c|c|}
\hline $\begin{array}{c}\text { Hydrogel } \\
\text { type }\end{array}$ & Bioink & $\begin{array}{l}\text { Crosslinking } \\
\text { Mechanism } \\
\text { in EBB }\end{array}$ & $\begin{array}{l}\text { Solidification } \\
\text { reversibility }\end{array}$ & EBB system & Advantages & Disadvantages & Sample tissue construct & Ref. \\
\hline 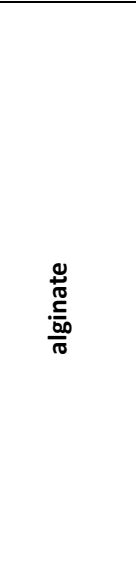 & $\begin{array}{c}\text { aggregates, } \\
\text { proteins, } \\
\text { encapsulated } \\
\text { cells (skeletal } \\
\text { myoblasts, } \\
\text { BMSC, SMC, } \\
\text { MSC, ASC, CPC, } \\
\text { chondrocytes, } \\
\text { cardiomyocytes) }\end{array}$ & ionic & - & $\begin{array}{c}\text { pneumatic } \\
\text { micro-extrusion } \\
\text { and bioplotter }\end{array}$ & $\begin{array}{l}\text { biocompatibility, good } \\
\text { extrudability and } \\
\text { bioprintability, fast } \\
\text { gelation, good stability } \\
\text { and integrality of } \\
\text { printed construct, } \\
\text { medium elasticity, low } \\
\text { cost, nonimmunogenic }\end{array}$ & $\begin{array}{l}\text { low cell adhesion } \\
\text { and spreading } \\
\text { without } \\
\text { modification of } \\
\text { hydrogel }\end{array}$ & $\begin{array}{l}\text { reproduced/adapted with } \\
\text { permission from Ref. [31] }\end{array}$ & $\begin{array}{l}31,34 \\
, 66,86 \\
, 136,1 \\
72,22 \\
2,223]\end{array}$ \\
\hline 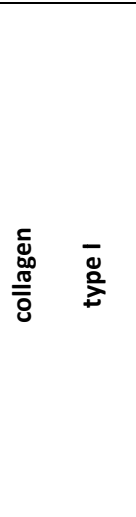 & $\begin{array}{c}\text { encapsulated } \\
\text { cells (bovine } \\
\text { aortic } \\
\text { endothelial cells, } \\
\text { keratinocytes, } \\
\text { fibroblasts, rat } \\
\text { neural cells, } \\
\text { MSC, AFS) }\end{array}$ & $\begin{array}{l}\mathrm{pH} \text {-mediated } \\
\text { or thermal }\end{array}$ & - & $\begin{array}{c}\text { pneumatic } \\
\text { micro-extrusion }\end{array}$ & $\begin{array}{l}\text { cell-adherent, promote } \\
\text { proliferation, signal } \\
\text { transducer, good } \\
\text { extrusion and } \\
\text { bioprinting abilities, } \\
\text { nonimmunogenic }\end{array}$ & $\begin{array}{l}\text { poor mechanical } \\
\text { properties, slow } \\
\text { gelation, } \\
\text { unstable }\end{array}$ & $\begin{array}{l}\text { reproduced/adapted with } \\
\text { permission from Ref. [103] }{ }^{\mathrm{a}}\end{array}$ & $\begin{array}{r}{[32,70} \\
, 72,10 \\
3,127, \\
129,2 \\
24,22 \\
5]\end{array}$ \\
\hline
\end{tabular}




\begin{tabular}{|c|c|c|c|c|c|c|c|c|}
\hline 惫 & $\begin{array}{l}\text { encapsulated } \\
\text { cells (HepG2, } \\
\text { hepatocytes, } \\
\text { fibroblasts, SMC) }\end{array}$ & thermal & + & $\begin{array}{l}\text { mechanical and } \\
\text { pneumatic } \\
\text { micro-extrusion }\end{array}$ & $\begin{array}{l}\text { cell-adherent, } \\
\text { biocompatibile, } \\
\text { nonimmunogenic }\end{array}$ & $\begin{array}{l}\text { unstable, fragile, } \\
\text { weak mechanical } \\
\text { properties at } \\
\text { physiological } \\
\text { temperature and } \\
\text { low abilities to } \\
\text { extrude and } \\
\text { print without } \\
\text { modification }\end{array}$ & permission from Ref. [25] ${ }^{\text {a }}$ & $\begin{array}{l}{[25,48} \\
, 66,10 \\
1,103 \\
226]\end{array}$ \\
\hline 总 & $\begin{array}{l}\text { encapsulated } \\
\text { cells (bone } \\
\text { marrow stem } \\
\text { cells or porcine } \\
\text { aortic valve } \\
\text { interstitial cells) }\end{array}$ & $\begin{array}{l}\text { ionic, } \\
\text { physical, or } \\
\text { covalent } \\
\text { agents }\end{array}$ & - & $\begin{array}{c}\text { pneumatic } \\
\text { micro-extrusion }\end{array}$ & $\begin{array}{l}\text { support cell viability, } \\
\text { biocompatibile, } \\
\text { nonimmunogenic, } \\
\text { widely used in tissue } \\
\text { engineering when } \\
\text { modified }\end{array}$ & $\begin{array}{l}\text { low proliferation } \\
\text { rate, low cell } \\
\text { adhesion, weak } \\
\text { mechanical } \\
\text { properties and } \\
\text { stability without } \\
\text { modification }\end{array}$ & $\begin{array}{l}\text { reproduced/adapted with } \\
\text { permission from Ref. [116] }\end{array}$ & $\begin{array}{c}{[116,1} \\
36]\end{array}$ \\
\hline 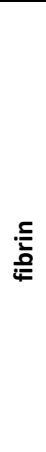 & $\begin{array}{c}\text { acellular } \\
\text { scaffolds or } \\
\text { encapsulated } \\
\text { cells (AFS, } \\
\text { HUVEC) }\end{array}$ & enzymatic & - & $\begin{array}{c}\text { pneumatic } \\
\text { micro-extrusion }\end{array}$ & $\begin{array}{l}\text { promote angiogenesis } \\
\text { (causes inflammatory } \\
\text { response), fast gelation, } \\
\text { good integrality, } \\
\text { medium elasticity }\end{array}$ & $\begin{array}{l}\text { difficult to } \\
\text { control } \\
\text { geometry, low } \\
\text { mechanical } \\
\text { properties, } \\
\text { limited EBB } \\
\text { printability }\end{array}$ & $\begin{array}{c}\frac{0.5 \mathrm{~cm}}{\text { image courtesy of Prof. Hosek }} \\
\text { from Czech Technical University in } \\
\text { Praque }^{\mathrm{b}}\end{array}$ & $\begin{array}{l}{[71,12} \\
9,150, \\
197]\end{array}$ \\
\hline
\end{tabular}




\begin{tabular}{|c|c|c|c|c|c|c|c|c|}
\hline 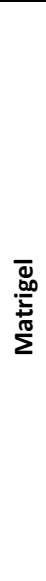 & $\begin{array}{l}\text { encapsulated } \\
\text { cells (HepG2, } \\
\text { BMSCs, gMSC, } \\
\text { gEPC) }\end{array}$ & thermal & - & $\begin{array}{c}\text { pneumatic } \\
\text { micro-extrusion }\end{array}$ & $\begin{array}{c}\text { promote cell } \\
\text { differentiation and } \\
\text { vascularization of } \\
\text { construct, support cell } \\
\text { viability, good } \\
\text { bioprintability, highly } \\
\text { suitable particularly for } \\
\text { cardiac tissue } \\
\text { engineering }\end{array}$ & $\begin{array}{c}\text { slow gelation, } \\
\text { which affects } \\
\text { mechanical } \\
\text { stability, require } \\
\text { cooling system } \\
\text { for EBB, } \\
\text { expensive }\end{array}$ & 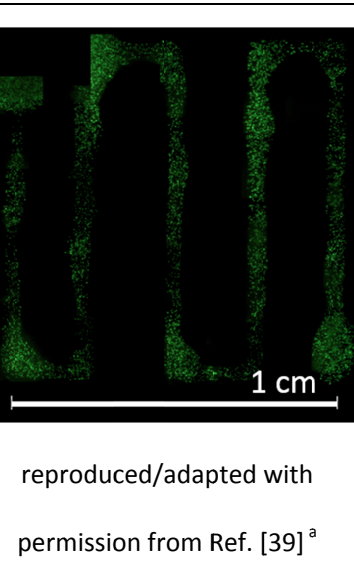 & $\begin{array}{l}39,13 \\
6,137]\end{array}$ \\
\hline 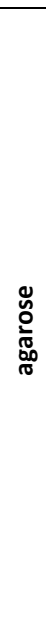 & $\begin{array}{l}\text { encapsulated } \\
\text { cells (BMSCs } \\
\text { osteosarcoma } \\
\text { cells, MSC) }\end{array}$ & thermal & + & $\begin{array}{l}\text { pneumatic and } \\
\text { mechanical } \\
\text { micro-extrusion }\end{array}$ & $\begin{array}{l}\text { high mechanical } \\
\text { properties, stable, } \\
\text { resistant for protein } \\
\text { adsorption, low cost, } \\
\text { good integrality, } \\
\text { nonimmunogenic }\end{array}$ & $\begin{array}{l}\text { low cell } \\
\text { adhesion, fragile, } \\
\text { require heating } \\
\text { system for EBB }\end{array}$ & reproduced/adapted with & $\begin{array}{c}{[70,12} \\
2]\end{array}$ \\
\hline 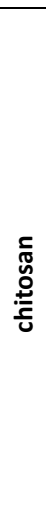 & $\begin{array}{c}\text { acellular } \\
\text { scaffolds, } \\
\text { encapsulated } \\
\text { cells (cartilage } \\
\text { progenitor cells, } \\
\text { MSC, CPC) }\end{array}$ & $\begin{array}{l}\text { ionic or } \\
\text { covalent } \\
\text { agents }\end{array}$ & - & $\begin{array}{c}\text { pneumatic } \\
\text { micro-extrusion }\end{array}$ & $\begin{array}{l}\text { antibacterial and } \\
\text { antifungal, medium } \\
\text { printability, } \\
\text { nonimmunogenic }\end{array}$ & $\begin{array}{l}\text { weak mechanical } \\
\text { and stability } \\
\text { properties } \\
\text { without } \\
\text { modification, } \\
\text { slow gelation } \\
\text { rate }\end{array}$ & permission from Ref. [97] ${ }^{\mathrm{a}}$ & $\begin{array}{c}{[70,86} \\
, 96,97 \\
]\end{array}$ \\
\hline
\end{tabular}




\begin{tabular}{|c|c|c|c|c|c|c|c|c|}
\hline 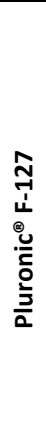 & $\begin{array}{c}\text { encapsulated } \\
\text { cells (human } \\
\text { primary } \\
\text { fibroblasts, } \\
\text { BMSC, HepG2) }\end{array}$ & thermal & + & $\begin{array}{l}\text { pneumatic and } \\
\text { mechanical } \\
\text { micro-extrusion }\end{array}$ & $\begin{array}{l}\text { high printability, good } \\
\text { bioprintability, } \\
\text { nonimmunogenic }\end{array}$ & $\begin{array}{l}\text { poor mechanical } \\
\text { and structural } \\
\text { properties, slow } \\
\text { gelation, rapid } \\
\text { degradation, } \\
\text { require heating } \\
\text { system for EBB }\end{array}$ & $\begin{array}{l}10 \mathrm{~mm} \\
\text { reproduced/adapted with } \\
\text { permission from Ref. [132] }{ }^{\mathrm{a}}\end{array}$ & $\begin{array}{r}{[72,13} \\
2,136 \\
227]\end{array}$ \\
\hline 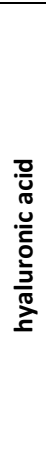 & $\begin{array}{c}\text { encapsulated } \\
\text { cells } \\
\text { (chondrocytes, } \\
\text { HepG2, C3A, } \\
\text { fibroblasts) }\end{array}$ & $\begin{array}{l}\text { ionic, } \\
\text { covalent } \\
\text { agents }\end{array}$ & - & $\begin{array}{l}\text { pneumatic and } \\
\text { mechanical } \\
\text { micro-extrusion }\end{array}$ & $\begin{array}{l}\text { promote proliferation } \\
\text { and angiogenesis, } \\
\text { fast gelation, good } \\
\text { bioprintability, } \\
\text { nonimmunogenic }\end{array}$ & $\begin{array}{c}\text { rapid } \\
\text { degradation, } \\
\text { poor mechanical } \\
\text { properties and } \\
\text { low stability } \\
\text { without } \\
\text { midofication }\end{array}$ & $\begin{array}{l}10 \mathrm{~mm} \\
\text { reproduced/adapted with } \\
\text { permission from Ref. [228 }{ }^{\mathrm{a}}\end{array}$ & $\begin{array}{c}{[45,10} \\
9]\end{array}$ \\
\hline 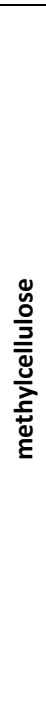 & $\begin{array}{l}\text { encapsulated } \\
\text { chondrocytes }\end{array}$ & $\begin{array}{c}\text { thermal, } \mathrm{pH}- \\
\text { mediated }\end{array}$ & + & $\begin{array}{c}\text { mechanical } \\
\text { micro-extrusion }\end{array}$ & $\begin{array}{l}\text { high printability, } \\
\text { nonimmunogenic }\end{array}$ & $\begin{array}{c}\text { low } \\
\text { bioprintability, } \\
\text { sensitive on } \\
\text { common cell } \\
\text { culture media, } \\
\text { unstable }\end{array}$ & permission from Ref. [144] & {$[144]$} \\
\hline
\end{tabular}

${ }^{\mathrm{a}}$ All samples figures are reprinted with permission from the respective publishers as indicated in the reference source. ${ }^{\mathrm{b}}$ Image courtesy of the author. 
Table 2

\begin{tabular}{|c|c|c|c|c|}
\hline & Bioprinter & Extrusion mechanism & $\begin{array}{l}\text { University / } \\
\text { Company }\end{array}$ & Use \\
\hline \multirow{8}{*}{ 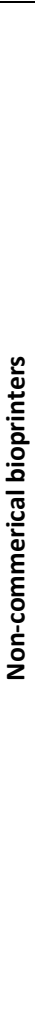 } & Modular Tissue Printing Platform & Pneumatic micro-extrusion & $\begin{array}{l}\text { Harvard Medical } \\
\text { School and KAIST }\end{array}$ & $\begin{array}{l}\text { Skin [32,224], fluidic channels [103], vascular network } \\
\text { [197], }\end{array}$ \\
\hline & Custom build 3D printer & Pneumatic micro-extrusion & $\begin{array}{l}\text { University of } \\
\text { Pennsylvania + MIT }\end{array}$ & Vascular network [196] \\
\hline & $\begin{array}{l}\text { multi-head tissue/organ building } \\
\text { system (MtoBS) }\end{array}$ & Pneumatic micro-extrusion & $\begin{array}{l}\text { The Catholic } \\
\text { University of Korea }\end{array}$ & $\begin{array}{l}\text { Liver [51], heart and adipose tissue [64], bone and cartilage } \\
{[186] \text {, and other heterogeneous tissues [229] }}\end{array}$ \\
\hline & 3D-axis Bioprinting System & Mechanical micro-extrusion & Korea University & Cell-free scaffold $[230,231]$, skin [232] \\
\hline & Multi-nozzle system & $\begin{array}{l}\text { Pneumatic, piezoelectric, } \\
\text { and solenoid micro-extrusion }\end{array}$ & Drexel University & Fibroblasts [16], endothelial cells [233] \\
\hline & Palmetto 3D Printer & Pneumatic micro-extrusion & Clemson University & $\begin{array}{l}\text { 3D vascular constructs [172], adipose-derived stem cells } \\
\text { [77] }\end{array}$ \\
\hline & Multi-Material 3D Bioprinting & Pneumatic micro-extrusion & $\begin{array}{l}\text { The Wyss Institute, } \\
\text { Harvard }\end{array}$ & Vasculature [27] \\
\hline & 3-D Scaffold Printer & Mechanical micro-extrusion & $\begin{array}{l}\text { Fraunhofer Institute } \\
\text { for Materials }\end{array}$ & Acellular scaffolds [143] \\
\hline
\end{tabular}




\begin{tabular}{|c|c|c|c|c|}
\hline & & & $\begin{array}{l}\text { Research and Beam } \\
\text { Technology }\end{array}$ & \\
\hline & Multi-Arm BioPrinter [80] & $\begin{array}{l}\text { Pneumatic and mechanical } \\
\text { micro-extrusion }\end{array}$ & University of lowa & Vascularized tissue printing [29], in-situ bone printing [205] \\
\hline & 3D Integrated Organ Printer & Pneumatic micro-extrusion & $\begin{array}{l}\text { Wake Forest } \\
\text { Institute for } \\
\text { Regenerative } \\
\text { Medicine }\end{array}$ & Keratinocytes [62], muscle [234] \\
\hline \multirow{9}{*}{ 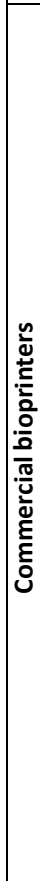 } & BioAssembly Tool & $\begin{array}{l}\text { Pneumatic and mechanical } \\
\text { micro-extrusion }\end{array}$ & Sciperio/nScrypt & Vascularization and skin [72] \\
\hline & NovoGen MMX Bioprinter & Mechanical micro-extrusion & Organovo & $\begin{array}{l}\text { Bone [235], liver [25,236,237], breast cancer [238], } \\
\text { vascularization }[25,193]\end{array}$ \\
\hline & 3D Discovery & Pneumatic micro-extrusion & RegenHU & Cartilage [144] \\
\hline & Biofactory & Pneumatic micro-extrusion & RegenHU & Air-blood tissue barrier [23] \\
\hline & 3D bioplotter & Pneumatic micro-extrusion & EnvisionTec & Bone [136], cell-free scaffold [239] \\
\hline & BioBots & Pneumatic micro-extrusion & Biobots & Vasculature [240] \\
\hline & BioAssembly Bot & Pneumatic micro-extrusion & Advanced Soluions & Human heart [188] \\
\hline & Fab@ Home & Mechanical micro-extrusion & Fab@home & $\begin{array}{l}\text { Liver [45], aortic valves [66], filling chondral and } \\
\text { osteochondral defects [73], and ear [241] }\end{array}$ \\
\hline & BioScaffolder & Pneumatic micro-extrusion & SYS+ENG & $\begin{array}{l}\text { Encapsulated proteins [31], heart [34], cartilage [47], } \\
\text { vascularization [137], and bone [242] }\end{array}$ \\
\hline
\end{tabular}



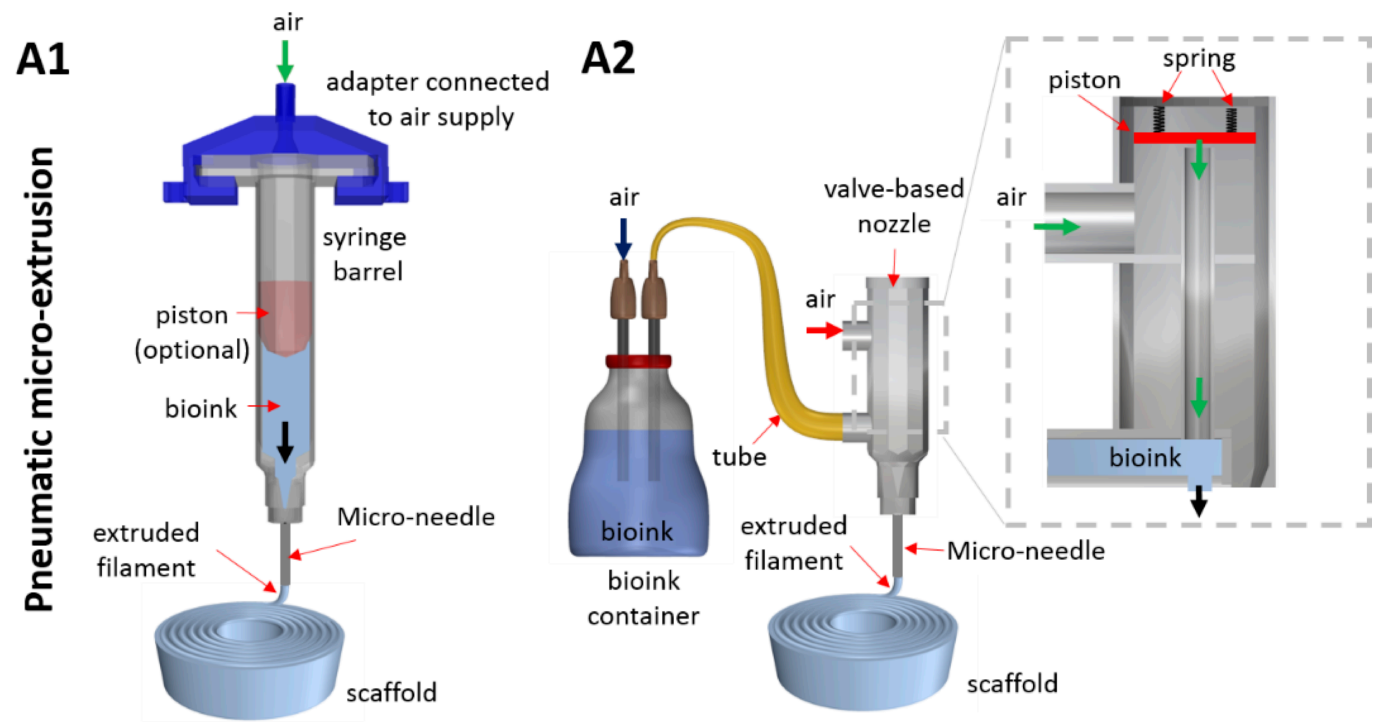

B1

B2
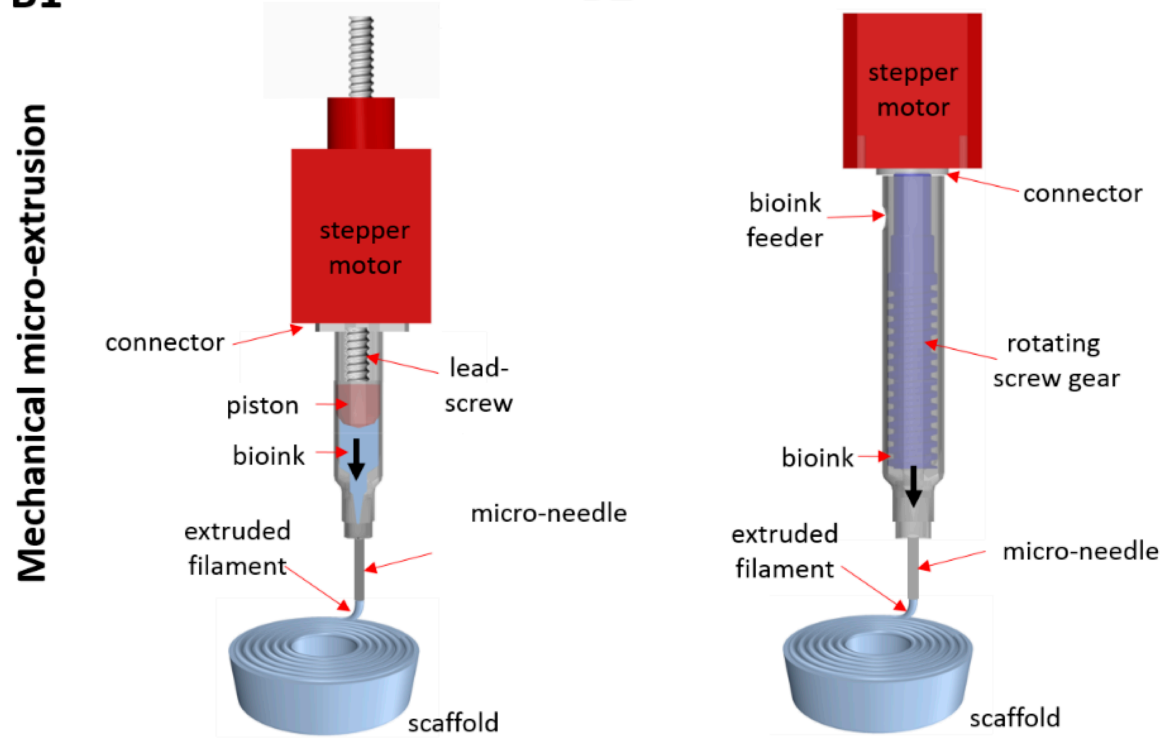

C

든

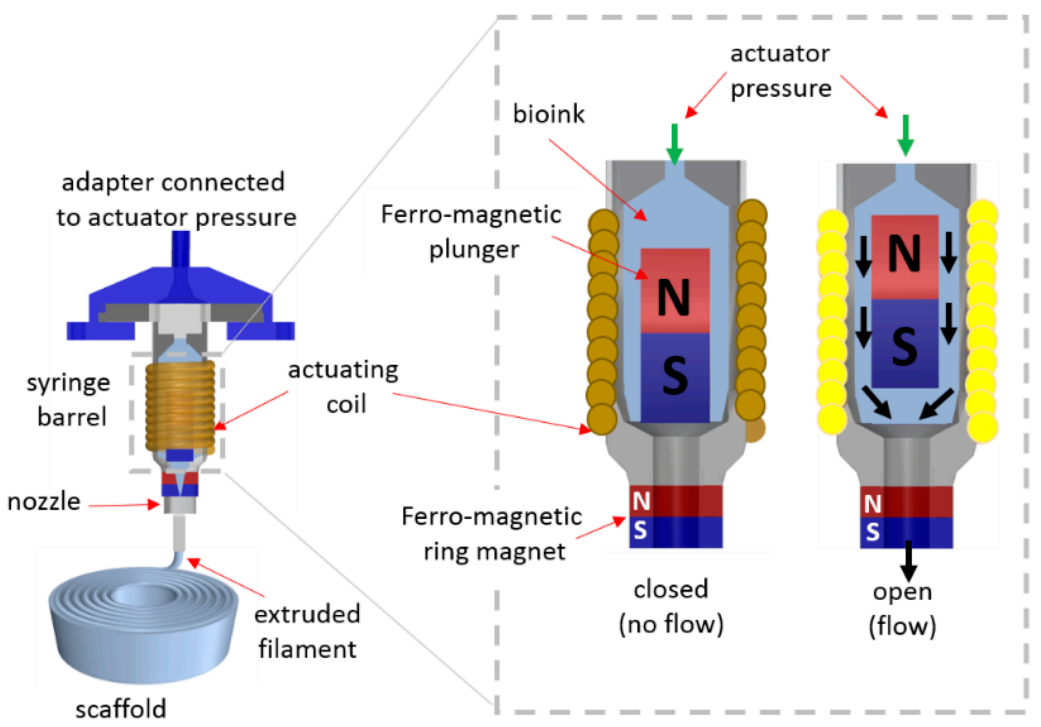


figure 2

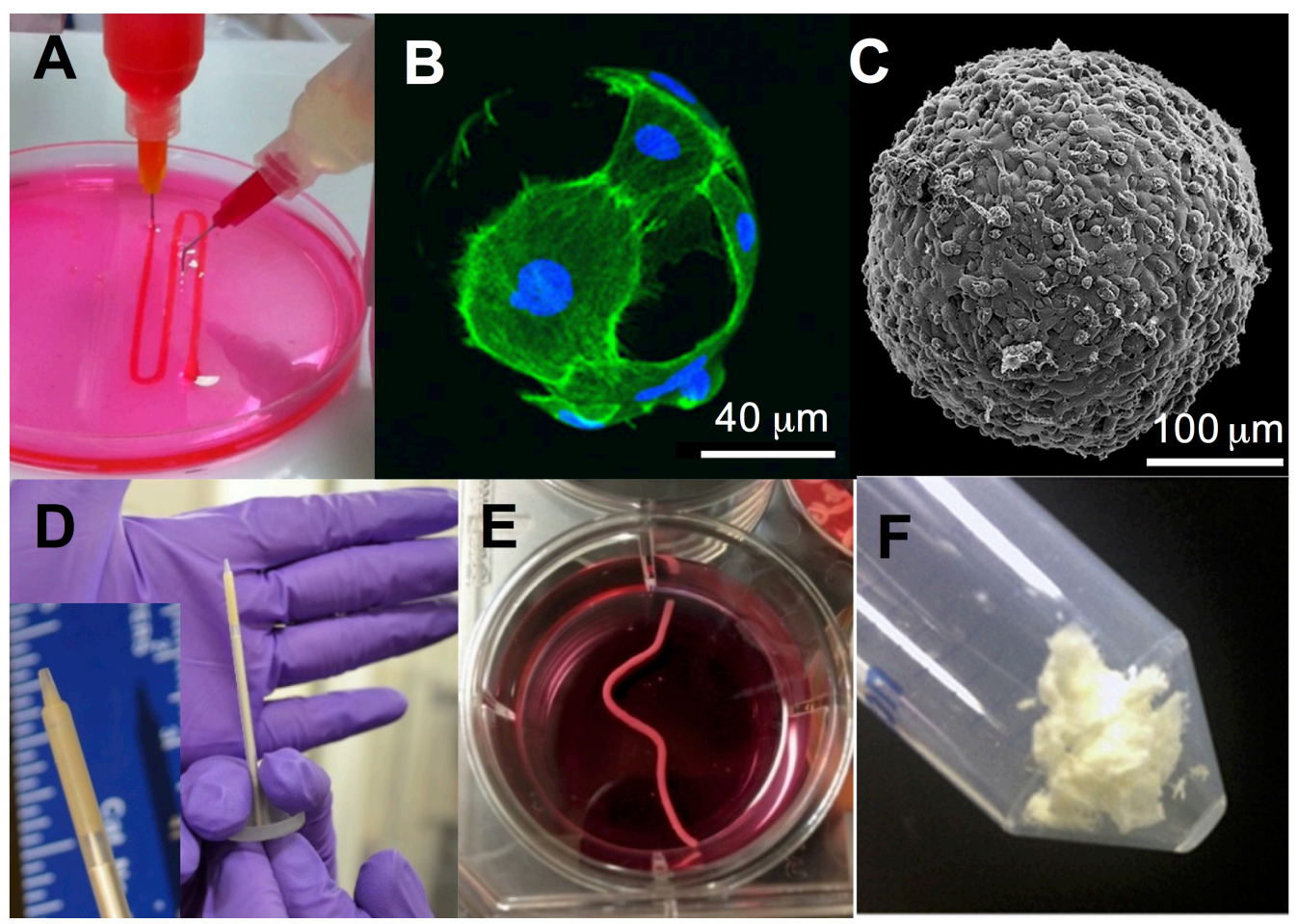




\section{figure 3}

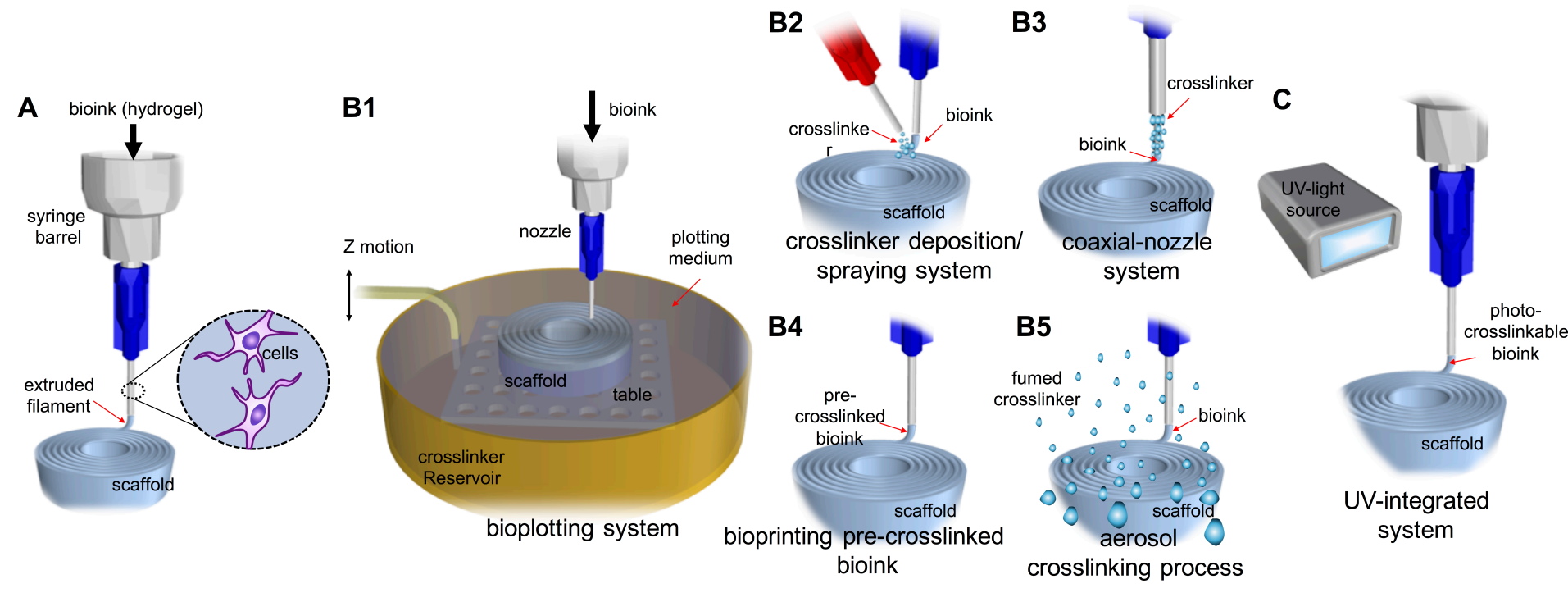

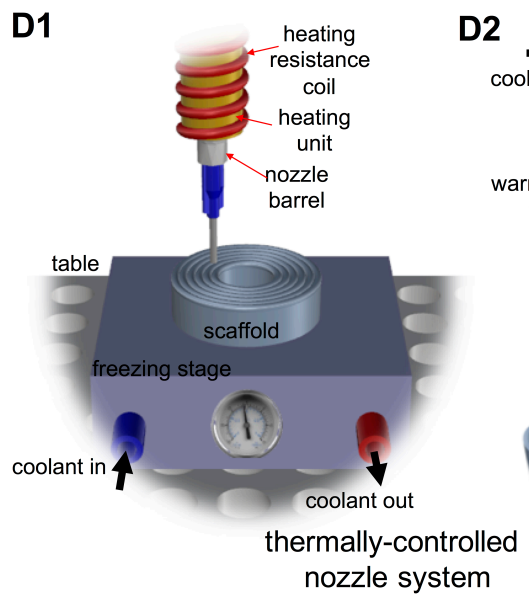

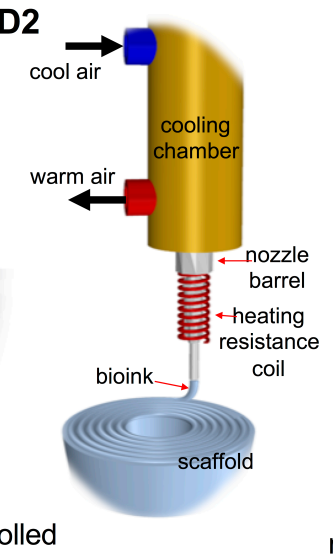

E

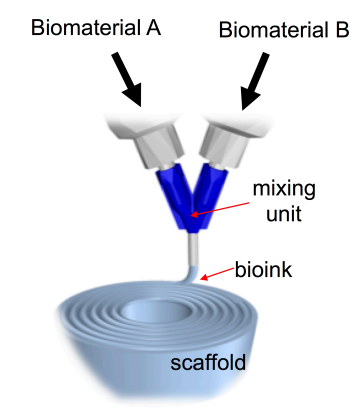

multi-chamber single-nozzle system
F Bioink

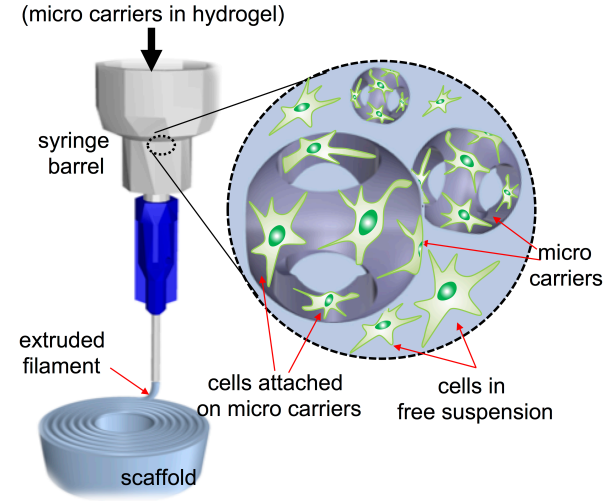

bioprinting micro-carriers
G1

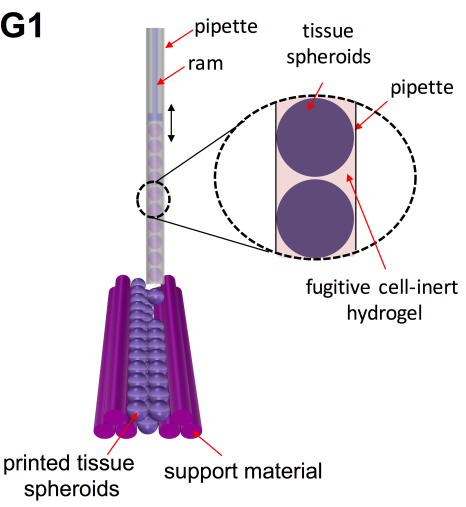

G2

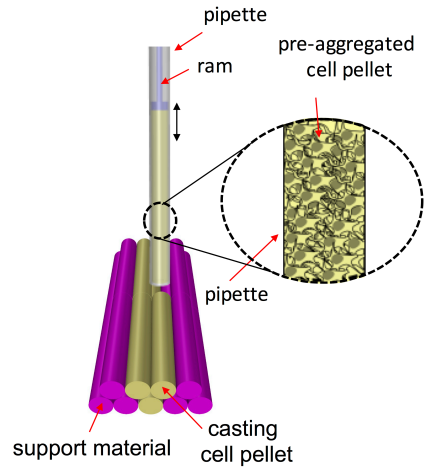

bioprinting cell aggregates

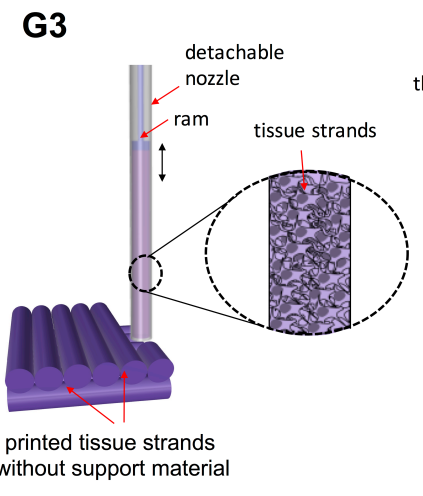

without support material

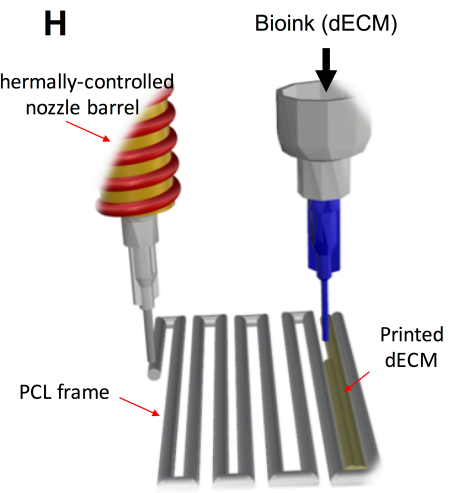

bioprinting dECM 
figure 4
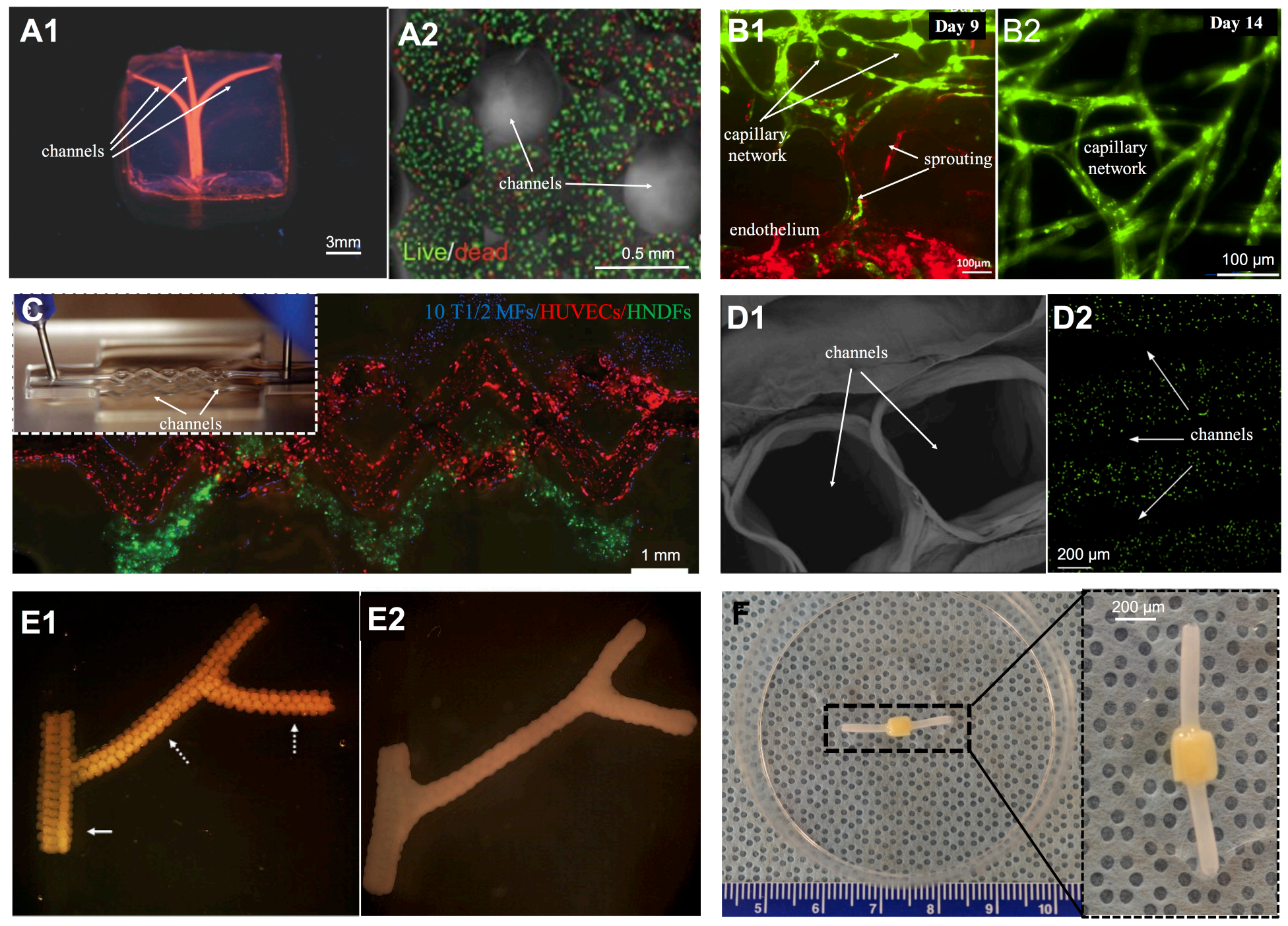
figure 5

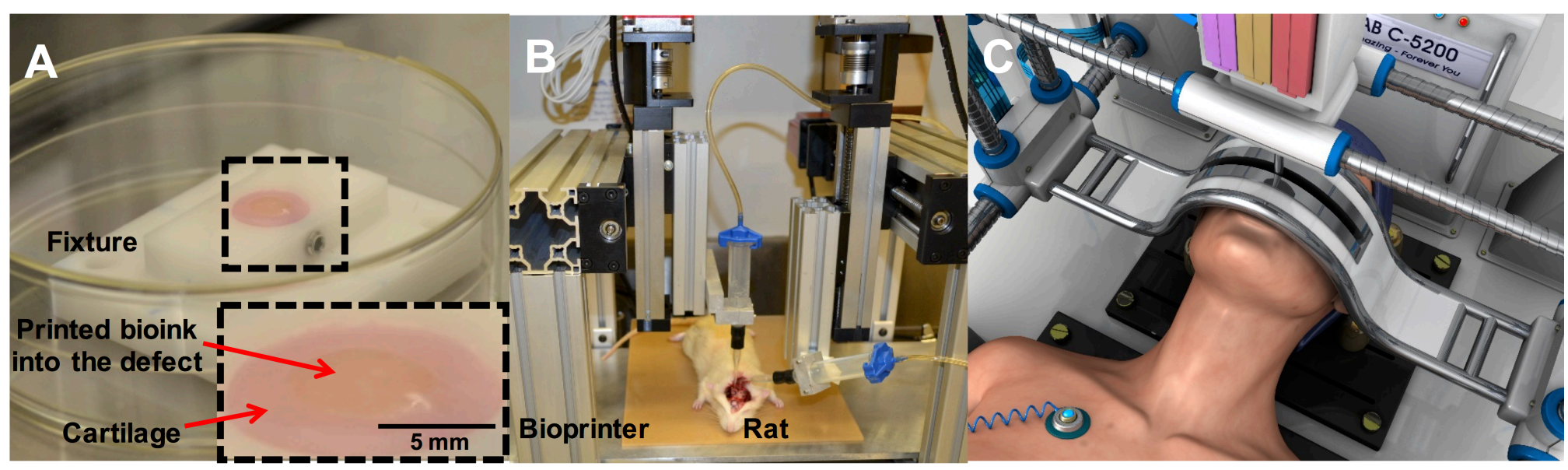


figure 6
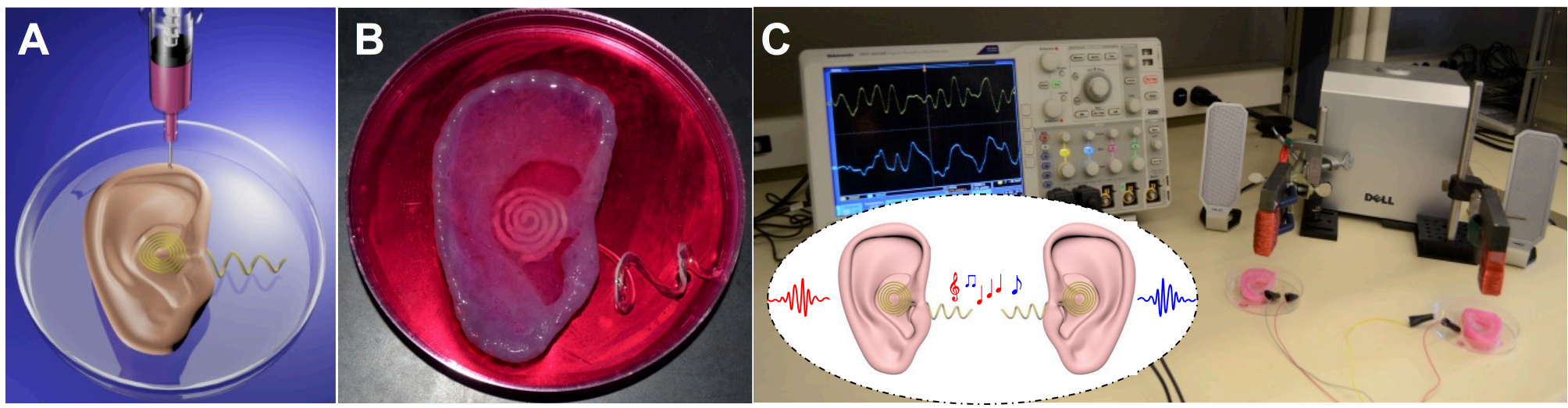